Portland State University

PDXScholar

Spring 1-1-2012

\title{
Distributed Solar Photovoltaic Grid Integration System : A Case Study for Performance
}

Ming Shen

Portland State University

Follow this and additional works at: https://pdxscholar.library.pdx.edu/open_access_etds

Part of the Oil, Gas, and Energy Commons, and the Power and Energy Commons Let us know how access to this document benefits you.

\section{Recommended Citation}

Shen, Ming, "Distributed Solar Photovoltaic Grid Integration System : A Case Study for Performance" (2012). Dissertations and Theses. Paper 945.

https://doi.org/10.15760/etd.945

This Thesis is brought to you for free and open access. It has been accepted for inclusion in Dissertations and Theses by an authorized administrator of PDXScholar. Please contact us if we can make this document more accessible: pdxscholar@pdx.edu. 
Distributed Solar Photovoltaic Grid Integration System - A Case Study for Performance

by

Ming Shen

A thesis submitted in partial fulfillment of the requirements for the degree of

\author{
Master of Science \\ in \\ Electrical and Computer Engineering
}

Thesis Committee:

Fu Li, Chair

James E. Morris

Xiaoyu Song

Portland State University

(C)2012 


\begin{abstract}
The need for the sustainable development of electricity, energy efficiency improvement, and environment pollution reduction has favored the development of distributed generation (DG). But problems come with increasing DG penetration in distribution networks. This thesis presents the Solar Energy Grid Integration System (SEGIS) Stage III project done by Portland General Electric (PGE), Advanced Energy, and Sandia National Lab on a selected distribution feeder of PGE. The feeder has six monitored commercial solar PV systems connected. The total power output from the PV systems could reach $30 \%$ of the feeder load. The author analyzes the performance of the solar feeder on both generation and voltage effects. As a project report, it introduced a new islanding detection done by other team members to give an islanding solution of future high penetration distribution network. Finally, the author describes micro-grid and grid support concept in SEGIS concept paper with some examples.
\end{abstract}




\section{Acknowledgement}

This thesis cannot be successful without helps from Portland State University (PSU), Portland General Electric (PGE) and the team of Solar Energy Grid Integration System (SEGIS) project. In this section, the key advisors, experts, engineers and supporters of the research will be mentioned.

First, my thanks goes to my thesis advisor, Professor Fu Li in Electrical Engineering and Computer Engineering (ECE) of PSU who generously took over the advisor role when my former advisor left suddenly. His extensive knowledge, vision and strong relationship with industry played a key role in the success of this work. It is my honor to be his student during my master's study. I would like to thank Dr. Robert Bass, the power engineering faculty in ECE of PSU, who helped me review the thesis and gave me his professional advice. I would also like to thank the other committee members, Prof. Xiaoyu Song and Prof. James Morris for their consideration and patience to arrange such a time in the midst of their work.

Second, the great support came from PGE is appreciated, especially, Dr. Wayne Lei, who the director of R\&D department and Mark Osborn, the smart grid manager, provided me with the opportunity to work for the SEGIS Stage III project. They also guided me to improve my thesis on both literary and professional aspects. Additionally, more helpful individuals I would thank at PGE in no particular order are: Robert Ferraro, Chris Steeprow, Ed Rainey, Kelly Cox, Bruce Barney, Joe Barra, Kat Teague and Jann Gilbert. Thanks go to all other people in PGE Dispatchable Standby Generation Department (DSGD). It was a nice experience to work with all of you. 
More, the literary style and grammar of this thesis was significantly improved from the expert advice and support of Jeff Maxwell.

Last but not least, I could not have learned about the synchrophasor technology without the paper "Interconnection Control of Distributed Generation With Time-Synchronized Phasors", from Mesa Scharf, Michael Mills-Price, the supervisor of the SEGIS project, and Dr. Michael Ropp, the president and principal engineer of Northern Plains Power Technologies (NPPT). I considered myself very fortunate to have had the opportunity to work with these two experts in the power field. 
Table of Contents

Abstract

Acknowledgement ii

Table of Contents $\quad$ iv

List of Tables

List of Figures $\quad$ vii

List of Abbreviations viii

Chapter 1 Introduction $\quad 1$

1.1 Introduction 1

1.2 Background 2

1.3 Overview $\quad 5$

1.4 Statement 5

Chapter 2 Solar Projects in PGE 6

2.1 Introduction $\quad 6$

2.2 Achievements on Solar Energy $\quad 6$

2.3 Current Tasks $\quad 10$

2.4 Summary 11

Chapter 3 Performance of the Selected Feeder 12

3.1 PGE Developed SCADA System - GenOnSys $\quad 12$

3.2 Feeder Performance in PV Generation $\quad 15$

3.2.1 Feeder Location and Radian Characteristics 15

$\begin{array}{ll}\text { 3.2.2 PV Generation Performance on the Feeder } & 17\end{array}$

3.3 Voltage Impact of PV Generation of the Feeder 18

$\begin{array}{ll}3.4 \text { Summery } & 21\end{array}$

Chapter 4 Island Detection with Synchrophasor $\quad 22$

Chapter 5 SEGIS Project for Grid Support and Micro-grid Operation 23

5.1 Micro-grid Operation 23

5.2 Grid support Function $\quad 24$

5.2.1 Over-voltage Mitigation $\quad 25$

$\begin{array}{ll}\text { 5.2.2 Under-voltage Mitigation } & 27\end{array}$ 
Chapter 6 Concluding Remarks $\quad 30$

6.1 Summary and Conclusion $\quad 30$

6.2 Future Research 31

$\begin{array}{ll}\text { Reference } & 33\end{array}$

Appendix Island Detection with Synchrophasor 35

1 Islanding $\quad 35$

$\begin{array}{ll}1.1 \text { Island and Islanding Effect } & 35\end{array}$

1.2 Intentional Islanding and Unintentional Islanding 36

1.3 Anti-islanding Strategy and Utilizing Islanding 38

2 Islanding Detection Methods 39

2.1 Islanding Detection Standards $\quad 39$

2.2 Standalone Detection Methods $\quad 40$

2.3 Communication Detection Methods 42

3 Synchrophasor-based Islanding Detection 44

4 Simulation Result for Synchrophasor-based Islanding Detection 47

4.1 EMTP Simulation $\quad 47$

4.2 RTDS Simulation $\quad 50$

5 SEGIS Demonstration $\quad 57$

6 Conclusion $\quad 58$ 


\section{List of Tables}

Table 1-1 Distributed Commercial/Industrial PV Project of PGE ................................................. 


\section{List of Figures}

Figure 1-1 Available Renewable Energy Compared to Global Energy Consumption 3

Figure 1-2 Total Primary Energy Supply from Sunlight ...................................... 3

Figure 2-1 Roof-top PV arrays at Kettle Foods building, Salem, OR .................... 7

Figure 2-2 ODOT Solar High Way Project at the I-5/I-205 Interchange................ 8

Figure 2-3 ProLogis rooftop PV arrays ........................................................... 10

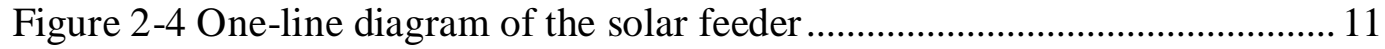

Figure 3-1 PGE SCADA system - GenOnSys. ................................................. 13

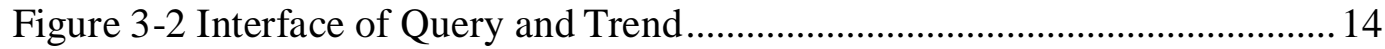

Figure 3-3 The selected feeder location............................................................ 15

Figure 3-5 PV generation amount of the feeder for Jul, 2010-Jun, 2011 ............... 16

Figure 3-6 Load Profile for Workday and Weekend ............................................ 17

Figure 3-7 Load profile and PV generation on the maximum PV production day 18

Figure 2-8 Feeder voltage profile...................................................................... 19

Figure 3-9 PV system structure for SEGIS ..................................................... 20

Figure 3-10 Financial incentives for renewable energy from Federal and Oregon20

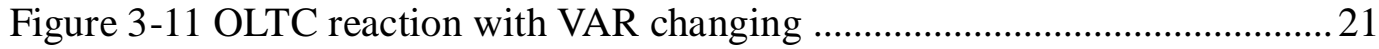

Figure 5-1 Overvoltage due to high penetration of PV ....................................26

Figure 5-2 VAR mode control to mitigate over-voltage .........................................26

Figure 5-4 Under-voltage due to high penetration of PV ...................................28 


\section{List of Abbreviations}

$\begin{array}{ll}\text { DG } & \text { Distributed Generation } \\ \text { DOE } & \text { Department of Energy } \\ \text { DSGD } & \text { Dispatchable Standby Generation Department } \\ \text { ECP } & \text { Electrical Connection Point } \\ \text { EMS } & \text { Energy Management System } \\ \text { EMTP } & \text { Electromagnetic Transients Program } \\ \text { EPS } & \text { Electrical Power System } \\ \text { EU } & \text { European Union } \\ \text { FEPC } & \text { Electric Power Companies of Japan } \\ \text { GPS } & \text { Globe Positioning System } \\ \text { HMI } & \text { Human-machine Interface } \\ \text { IEC } & \text { International Electrical Commission } \\ \text { IEEE } & \text { Institute Electrical and Electronics Engineer } \\ \text { LVRT } & \text { Low Voltage Ride Through } \\ \text { OLTC } & \text { On-load Tap Changer } \\ \text { PGE } & \text { Portland General Electric } \\ \text { PMU } & \text { Phasor Measurement Unit } \\ \text { PV } & \text { Photovoltaic } \\ \text { RPS } & \text { Renewable Portfolio Standard } \\ \text { RTDS } & \text { Real Time Digital Simulator } \\ \text { SCADA } & \text { Supervisory Control and Data Acquisition } \\ \text { SEGIS } & \text { Solar Energy Grid Integration Systems } \\ \text { SEL } & \text { Schweitzer Engineering Laboratories } \\ \text { SNL } & \text { Sandia National Laboratories } \\ \text { NPPT } & \text { Northern Plains Power Technologies } \\ \text { VMF } & \text { Voltage Magnitude and Frequency } \\ & \\ & \end{array}$




\section{Chapter 1 Introduction}

\subsection{Introduction}

On August 12, 2008, the U.S. Department of Energy (DOE) announced that it would invest up to $\$ 24$ million in Fiscal Year 2008 and beyond to develop solar energy products to significantly accelerate penetration of solar photovoltaic (PV) systems in the U.S. The Solar Energy Grid Integration Systems (SEGIS) [7] projects will provide critical research and development funding to develop less expensive, higher performing products to enhance the value of solar PV systems to homeowners and business owners. DOE awarded 12 industry teams to participate in cost-shared cooperative agreements focusing on conceptual designs of hardware component, and market analysis, through Sandia National Laboratories (SNL). As recipients of Solar Program funding, each company completed Stage I conceptual designs and market analysis. Each project was then evaluated on its likelihood of success, the potential for commercialization, and the ability to accelerate integration of solar PV technologies, prior to receiving a second round of funding. In 2009 , five of these companies received additional funding of $\$ 11.8$ million to step to the next stage of SEGIS. In September 2010, four organizations were awarded the final stage funding which was $\$ 8.5$ million dollars [8].

As one of the four, Advanced Energy (AE) (Bend, OR), which is an innovation leader for grid tied PV inverters in the residential, commercial and utility markets, is partnering with Portland General Electric (PGE), Northern Plains Power Technologies (NPPT), and Schweitzer Engineering Laboratories (SEL) to approach targets for the SEGIS Stage III program, including: 1) commercialization of new algorithms to optimize 
the energy harvest of the inverter and PV system; 2) advanced communications technologies that enable distributed PV systems to communicate with power utilities, and 3) next-generation controls functionality that will allow utilities to manage networks of distributed power sources.

\subsection{Background}

As standards and living increase worldwide, the demand for energy in all forms also increases. Today the world faces three energy crises. The first crisis is that there is a high dependency on fossil fuels which leads to its exploitation for energy which in turn, can do significant damage to the environment at almost all stages of production and use. The second crisis is that we have consumed about half of the world's total recoverable oil reserves and deforested significant areas of the world; neither of these practices is sustainable. The third crisis is that even with this global exploitation of fossil fuels and biomass for energy, large populations of humanity lack the energy access to even boil water. Yet we have energy. "Mostly thanks to the Sun, the world also has a renewable usable energy flux that exceeds 120 PW (8,000 times 2004 total usage), or $3.8 \mathrm{YJ} / \mathrm{yr}$, dwarfing all non-renewable resources." [1] 


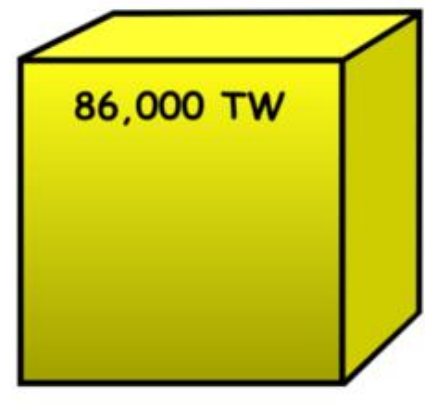

Solar
870 TW

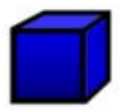

Wind

32 TW

日

Geothermal

\section{TW}

Global

Consumption

Figure 1-1 Available Renewable Energy Compared to Global Energy Consumption [1]

In Figure 1-1[2], boxes represent different forms of energy on the earth. We see the box of solar energy is 86,000 terawatts $(1$ terawatt $=$ trillion watts), significantly greater than wind energy at 870 terawatts, geothermal at 32 terawatts, and human consumption at only 15 terawatts. Figure 1-2 represents the distribution of solar energy on the planet [3]. Most people on earth live where there is plenty of sun; South and Central America, Africa, Middle East, South Asia, and the Mediterranean all receive significant amounts of solar energy. The amount of solar energy collected at the blue dots in Figure 1-2 would equal 18 terawatts if converted at only 9 percent efficiency.

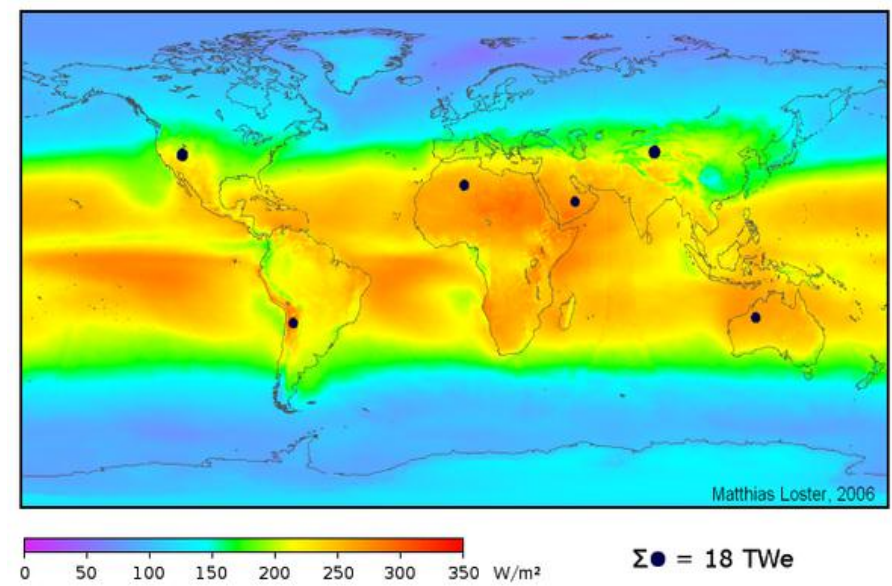

Figure 1-2 Total Primary Energy Supply from Sunlight

An increasing number of countries are starting to deploy development plans for solar 
power. Some instances are presented below.

Japan started its residential photovoltaic program implementation "Monitoring Program for Residential PV system" from 1994 to 1996, followed by the "Program for the Development of the Infrastructure for the Introduction of Residential PV Systems", which has been running since 1997. In June 2006, the Japanese "New National Energy Strategy" confirmed the political support for renewable energies. One of the largest programs was announced by the Tokyo Metropolitan Government which plans to support the installation of $1 \mathrm{GW}$ of PV systems at 40,000 households in 2009 and 2010. The federation of Electric Power Companies of Japan (FEPC) announced that they intend to install PV plants with a cumulative installed capacity of $10 \mathrm{GW}$ by 2020 [4].

In China, the solar PV industry grew rapidly during the country's $11^{\text {th }}$ Five-Year Plan (2006-2010). China's solar wafer capacity in 2011 grew by $81 \%$ to reach $35 \mathrm{GWp}$ ( $W_{p}$ is the unit for the power at peak point) and silicon-based solar cell capacity in 2011 grew by $113 \%$ to reach $37.3 \mathrm{GWp}$ [5]. During the $12^{\text {th }}$ Five-Year Plan period (2011-2015), the PV installation will grow by tenfold to reach the target of $10 \mathrm{GWp}[6]$.

In the European Union (EU), the installations of photovoltaic systems increased more than ten times between 2001 and 2007 and reached $4.7 \mathrm{GW}$ of cumulative installed capacity at the end of 2007. During the $23^{\text {rd }}$ European Photovoltaic Solar Energy Conference and Exhibition from $1^{\text {st }}$ to $5^{\text {th }}$, Sept. 2008, the new vision of the European Photovoltaic Industry Association for 2020 was presented. The Association aims to develop the sector in such a way that 6 to $12 \%$ of European electricity should then be generated with PV systems. This would correspond to 210 to $420 \mathrm{TWh}$ of electricity or 175 to $350 \mathrm{GWp}$ installed capacity of PV electricity systems. 


\subsection{Overview}

This paper focuses on performance of a solar feeder with $30 \%$ penetration (ideal) and concomitant issues for practical solar system operation. Chapter 1 addresses the importance of solar energy and current PV development in the US and other countries. An introduction to the SEGIS project is also presented. Chapter 2 gives an introduction of PGE's current commercial solar sites and a brief overview on PGE's achievements on the SEGIS project. Chapter 3 represents the performance study of the solar feeder on power generation; feeder voltage and on-load tap changer (OLTC) under various conditions. A new method of islanding detection for distributed generation (DG) is also introduced with comparison with conventional methods in Chapter 4 and this is applied to a distributed PGE PV grid integrated site for a real case study. Chapter 5 presents more functions of a PV system at a high penetration level. Conclusions of the study are summarized in Chapter 6 followed by discussion of some ideas on future work.

\subsection{Statement}

This paper was required by PGE as a project report for the SEGIS program. I cited part III-V of the paper "Interconnection Control of Distributed Generation With Time-Synchronized Phasors" by Michael Mills-Price and Michael Ropp, etc. to introduce the synchrophasor technology in islanding detection application in the Appendix. To give a complete picture of the project, I listed the Appendix as Chapter 4 in the Table of the Contents. My contributions to the project are described in Chapter 3 and Chapter 5, which focus on solar feeder performance analysis, solar sites issues, and opinions on future high-penetration PV network. 


\section{Chapter 2 Solar Projects in PGE}

\subsection{Introduction}

PGE is a fully integrated electric utility that was established in 1889. Today PGE has 4,000 square mile service territory with a population of some $1,663,000$ people and more than 818,000 residential, commercial and industrial customers. It is Oregon's largest electric utility. Because Oregon is a very environmentally conscientious state, it should come as no surprise that PGE generates over $10 \%$ of its electricity with renewable resources. Such an aggressive posture puts the utility well on its way to meeting the Oregon Department of Energy's Renewable Portfolio Standard (RPS) of 25\% by 2025. [9]

\subsection{Achievements on Solar Energy}

As a pioneer in distributed solar energy resources, PGE has been working on solar projects for years. In 2003, PGE helped Kettle Foods, Inc., Oregon's homegrown producer of Kettle ${ }^{\mathrm{TM}}$ brand Potato Chips, to install a 114-kilowatt PV system on the roof of its Salem facility. The array - the largest in the Pacific Northwest when it was installed - produces clean, renewable energy in a state best know for its raining weather. It saves the firm $\$ 8,400$ in energy costs each year and will avoid 2,500 tons of $\mathrm{CO}_{2}$ emission over the life of the system. [10] 


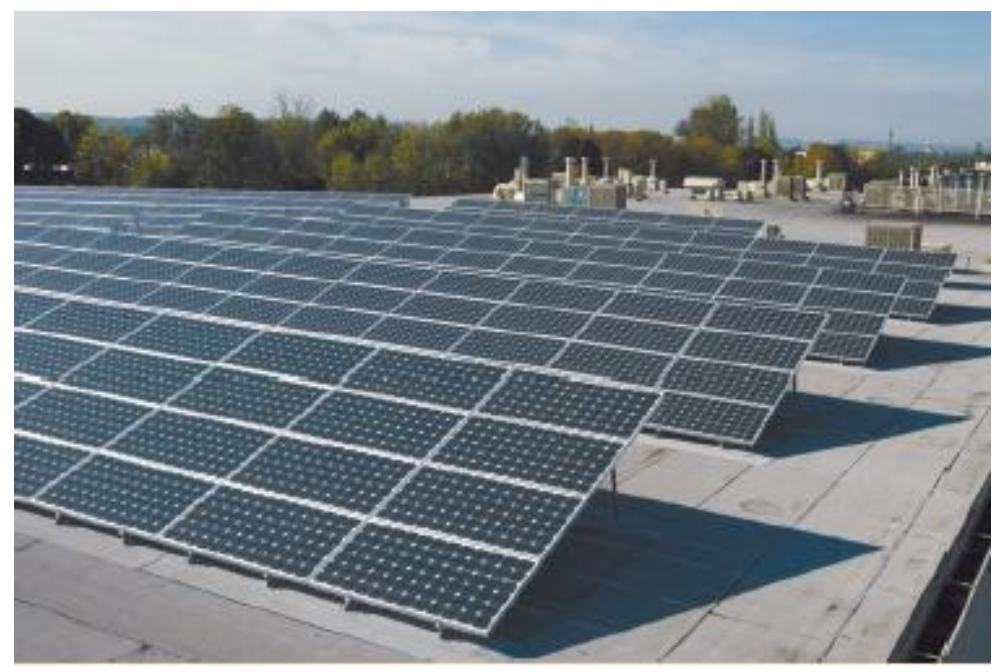

Figure 2-1 Roof-top PV arrays at Kettle Foods building, Salem, OR

In 2008, PGE was recognized by the Solar Electric Power Association (SEPA) as a utility leader in the integration of solar into its generation portfolio. PGE ranked eighth of the "2008 Top Ten Utility Solar Integration Rankings", and fourth in the West in total solar megawatts. The annual rankings are based on the amount of solar electricity installed during the 2008 calendar year. PGE integrated more than 3.5 megawatts AC of solar power into its system, more than tripling the amount of solar resources connected to its system. Among the total solar capacity installed that year, there were two major solar installations in Oregon: the nation's first solar highway project at the I-5/I-205 interchange in Tualatin and the Northwest's largest rooftop installation in Portland.

The solar highway demonstration project, a collaboration by PGE, US Bank and the Oregon Department of Transportation, began supplying renewable power in December 2008 to help light the way for drivers at the I-5 and I-205 interchange in Tualatin. The 104-kilowatt photovoltaic system covers about 8,000 square feet - roughly the area of two footballs fields - and produces about 112,000 kilowatt hours a year, or 28 percent of the 400,000 kilowatt hours used to light the interchange; actual performance has been 
better than predicted. [36]

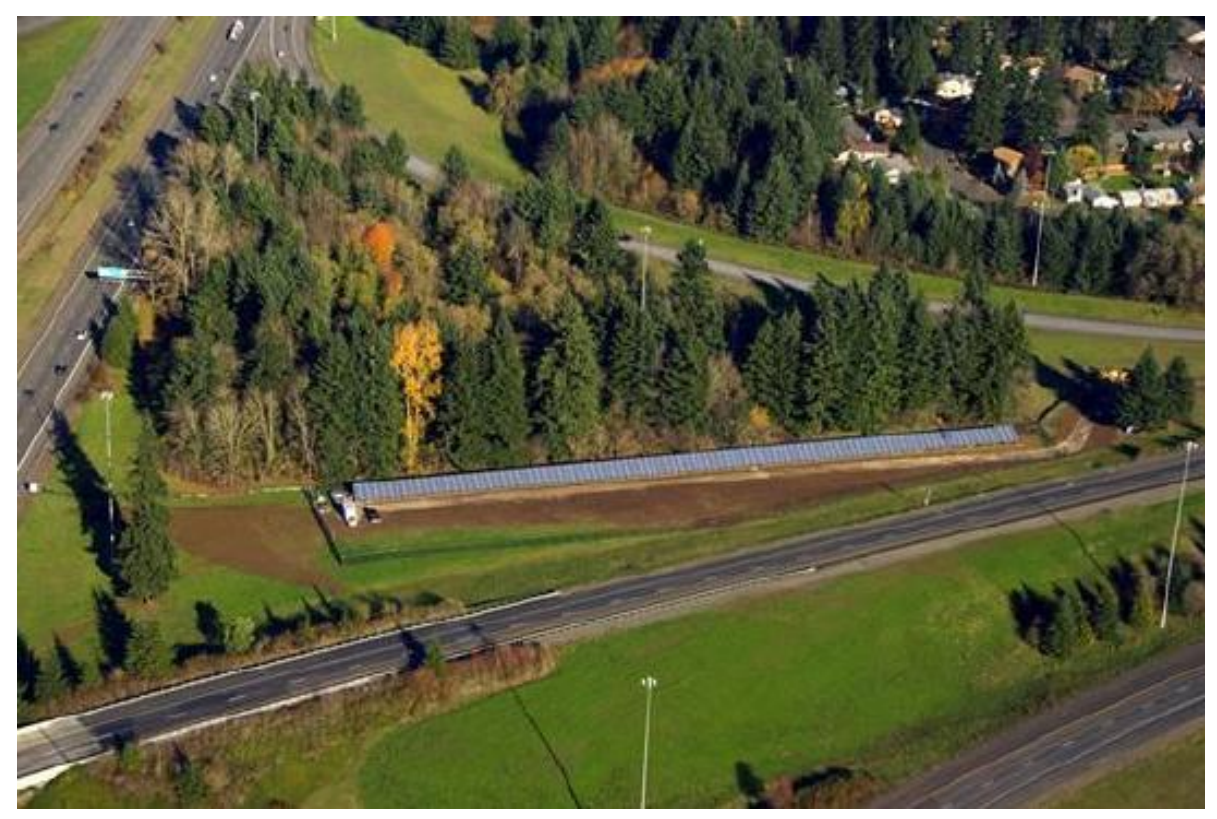

Figure 2-2 ODOT Solar High Way Project at the I-5/I-205 Interchange

The largest rooftop solar project in the Pacific Northwest is a component of the SEGIS project. As introduced in Chapter 1, PGE is part of a team - led by Advanced Energy, and including industry experts Schweitzer Engineering Laboratories (SEL) and Northern Plains Power Technologies - that is working on a subset of issues linked to high penetration of a PV system that is integrated into the utility grid.

The project managed by PGE and co-funded by U.S. Bank and ProLogis is also named the "ProLogis project". As the world's largest owner, manager and developer of distribution facilities, ProLogis, also owns the most roof space in the Portland region. It covers 10 ProLogis distribution warehouses in the Portland area with thin-film solar panels. The whole project is composed of three stages.

The first stage of the project comprised three buildings in the industrial zone along the Columbia River near Portland International Airport. The combined solar footprint of this 
installation is more than $464,000 \mathrm{sq} \mathrm{ft}(43,107 \mathrm{sq} \mathrm{m})$, with a generation capacity of 1.1 MW.

Completed in December 2008, the installation took only three months from agreement to production ready. The PV panels use thin-film amorphous silicon technology and are integrated into the building roofs. Such panels are lighter than crystalline solar panels, do not require separate racking for support and allow for rapid installation.

The second stage of the project included seven more buildings in three different ProLogis parks. This second-stage installation covered more than $906,000 \mathrm{sq} f \mathrm{ft}(84,170 \mathrm{sq}$ m) and added another 2.4 MW of generation capacity. Stage two began construction in March 2010 and came on-line in July 2010, using the same thin-film technology as the previous stage.

Table 1-1 Distributed Commercial/Industrial PV Project of PGE

\begin{tabular}{|c|c|c|c|c|}
\hline $\begin{array}{c}\text { Name of PV } \\
\text { System }\end{array}$ & Capacity & Location & $\begin{array}{c}\text { Land } \\
\text { Area }\end{array}$ & In Service since \\
\hline Kettle Foods & $114 \mathrm{~kW}$ & Salem & --- & 2003 \\
\hline $\begin{array}{c}\text { ODOT Highway } \\
\text { Pabilitation } \\
\text { Center }\end{array}$ & $104 \mathrm{~kW}$ & $\begin{array}{c}\text { I-5/I-205 } \\
\text { Interchange }\end{array}$ & $8,000 \mathrm{sq} \mathrm{ft}$ & 2008 \\
\hline $\begin{array}{c}\text { Prologis E1 } \\
\text { E2 }\end{array}$ & $858 \mathrm{~kW}$ P4
\end{tabular}

In October 2009, the Solar Electric Power Association (SEPA) selected the first stage of this project as the winner of the SEPA Solar Business Achievement Award in the

\footnotetext{
${ }^{*}$ Distributed solar system on SEGIS project research feeder
} 
category "Partnering for Success." [11]

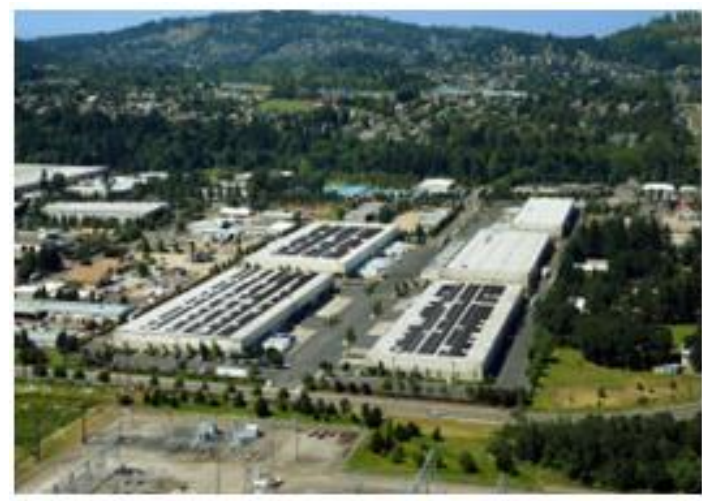

(a)

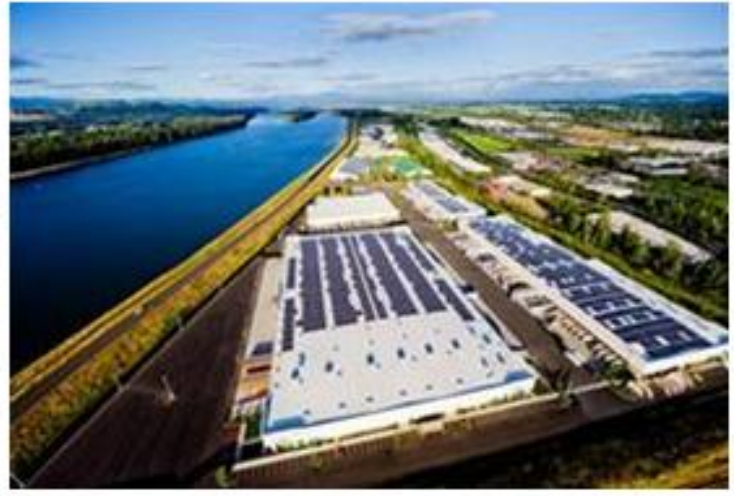

(b)

Figure 2-3 ProLogis rooftop PV arrays (a) ProLogis buildings in Gresham (b) ProLogis buildings along the Columbia River

\subsection{Current Tasks}

As presented in Chapter 1, the SEGIS project has entered on its third stage. Also, PGE is involved in this third stage development with Advanced Energy. Overall, PGE continue to work through issues and other concerns relating to smart grid infrastructure. For example, some of the developments are necessary to support a fundamental shift in the nation's power infrastructure from a relatively small set of centralized generating resources to a highly distributed network of power sources of different types. These new topologies require grid support for capabilities such as low-voltage ride-through (LVRT), maintaining grid voltage and economical island detection [12]. For the SEGIS project, PGE and Advanced Energy selected a feeder that features 30\% PV penetration. The project will investigate feeder performance monitoring and island detection testing. The feeder has 6 of the monitored PV sites mentioned above with 2.5 MW interconnected to the grid. The total load on the feeder is 7.5 MW in summer and 8.5 MW in winter. Figure 2-4 is the one-line diagram of the feeder. 


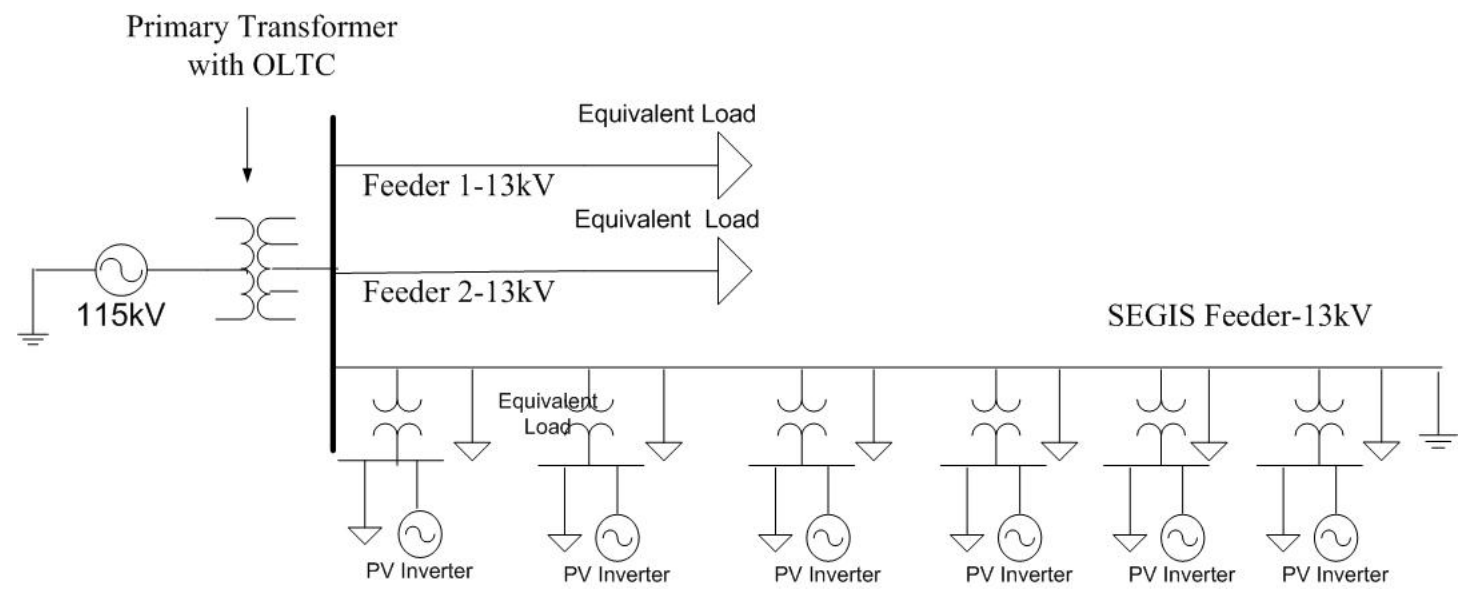

Figure 2-4 One-line diagram of the solar feeder

\subsection{Summary}

This chapter summarized PGE's commercial distributed PV generations and presented the SEGIS project task on PGE side. The selected project feeder diagram was illustrated to show the feeder's configuration. 


\section{Chapter 3 Performance of the Selected Feeder}

As the selected distribution feeder for the SEGIS project is the one with most number of commercial grid-integrated PV systems in Oregon, there is great interest regarding the power generation and voltage behavior at the feeder under high PV power output conditions. A system of supervisory control and data acquisition (SCADA), called GenOnSys, is used to monitor distributed generation system and collect system data.

\subsection{PGE Developed SCADA System - GenOnSys}

GenOnsys is a SCADA system developed by the PGE Dispatchable Standby Generation Department (DSGD). It is based on the Wonderware System Platform and InTouch human-machine interface (HMI) environment for its DGs. The system displays DG sites information and data from the server of the Energy Management System (EMS) which collects data from each distributed resource onto the screens in the command center in the form of numbers, graphics, and electrical schematics. Figure 3-1 shows the HMI of GenOnSys through WindowView application: Figure 3-1a is the PV site under monitoring, Figure $3-1 b$ is the overview map of all distributed resources. In addition to PV systems, PGE is monitoring other DGs such as diesel/turbine backup generators (Figure 3-1c), wind turbines (Figure 3-1d), hydro power generators (Figure 3-1e), and a bio fuel power system(Figure 3-2f) as well. Another two tools of applications, Quary and Trend, support all data and parts of the graphics provided in this thesis (Figure 3-2). Query is a tool which Wonderware provides to find data of query conditions. Trend shows the graphic curve for 
the chosen data tags in a time period selected by the user.

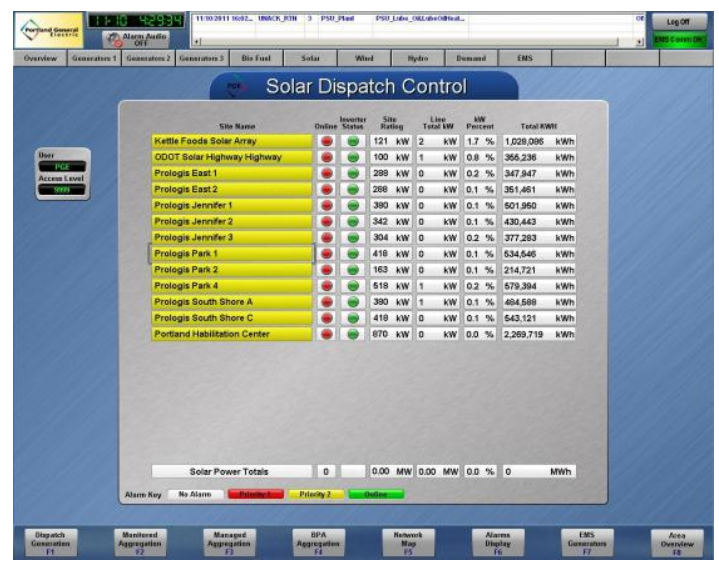

(a)

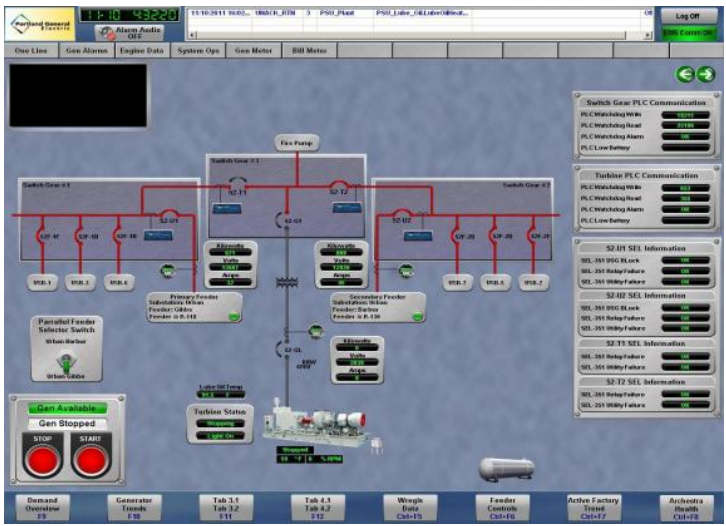

(c)

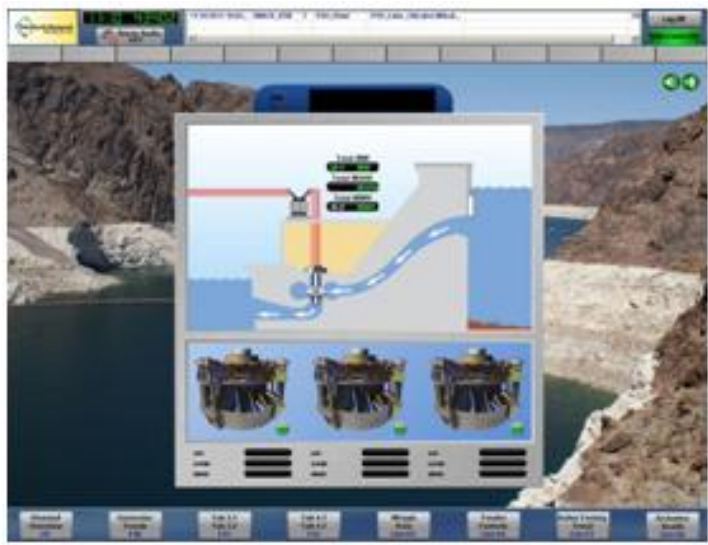

(e)

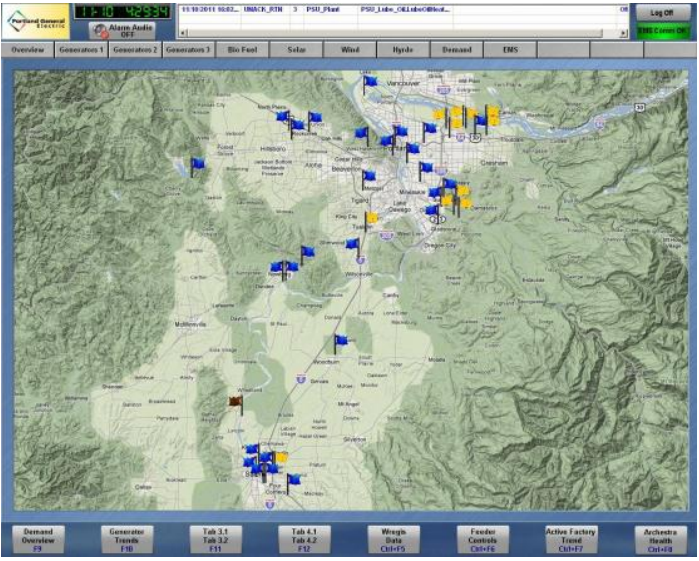

(b)

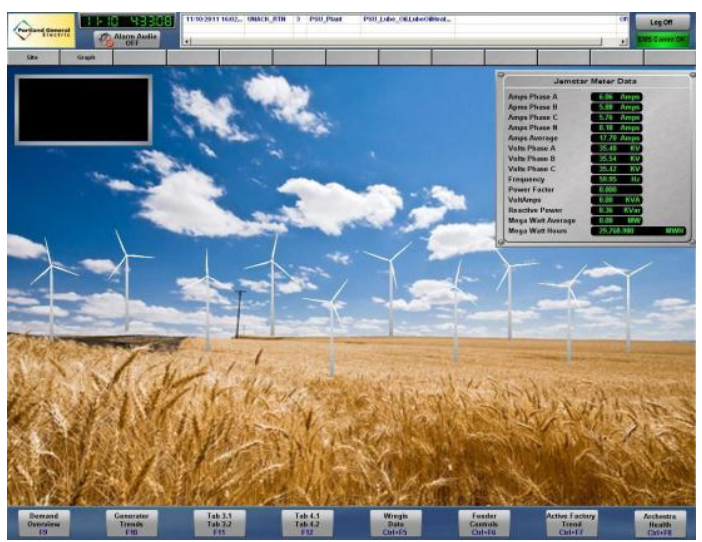

(d)

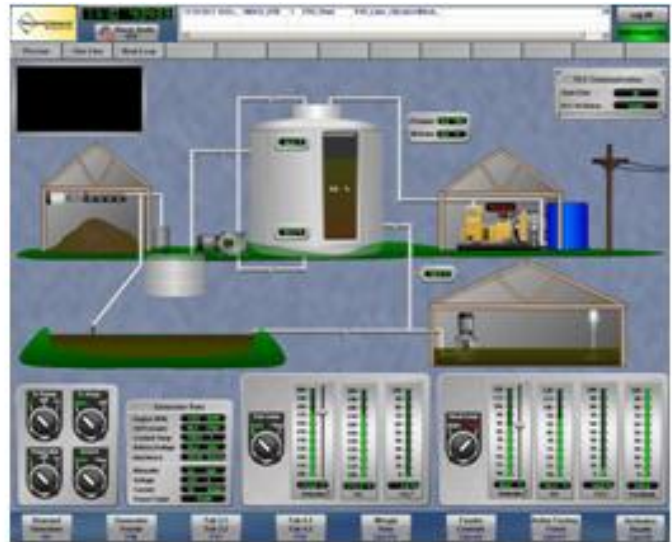

(f)

Figure 3-1 PGE SCADA system - GenOnSys (a) PV System in GenOnSys (b) Overview of current DG of PGE (c) Diesel turbine generator (d) Wind turbines (e) Hydro power generators (f) Bio fuel power 
generation system

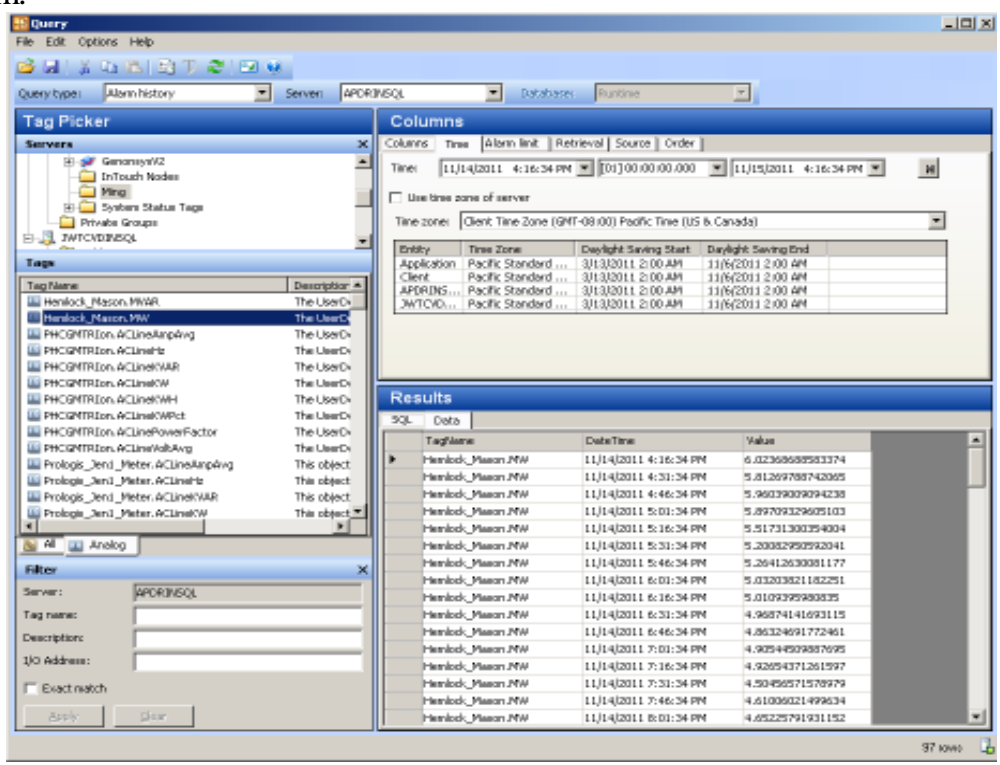

(a)

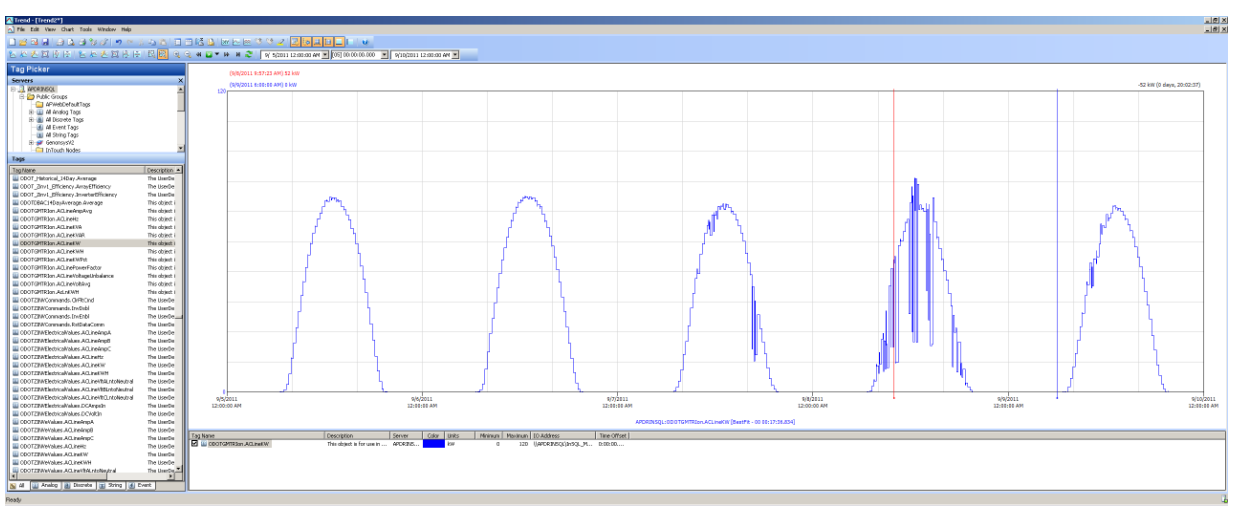

(b)

Figure 3-2 Interface of Query and Trend (a) Query (b) Trend 


\subsection{Feeder Performance in PV Generation}

\subsubsection{Feeder Location and Radian Characteristics}

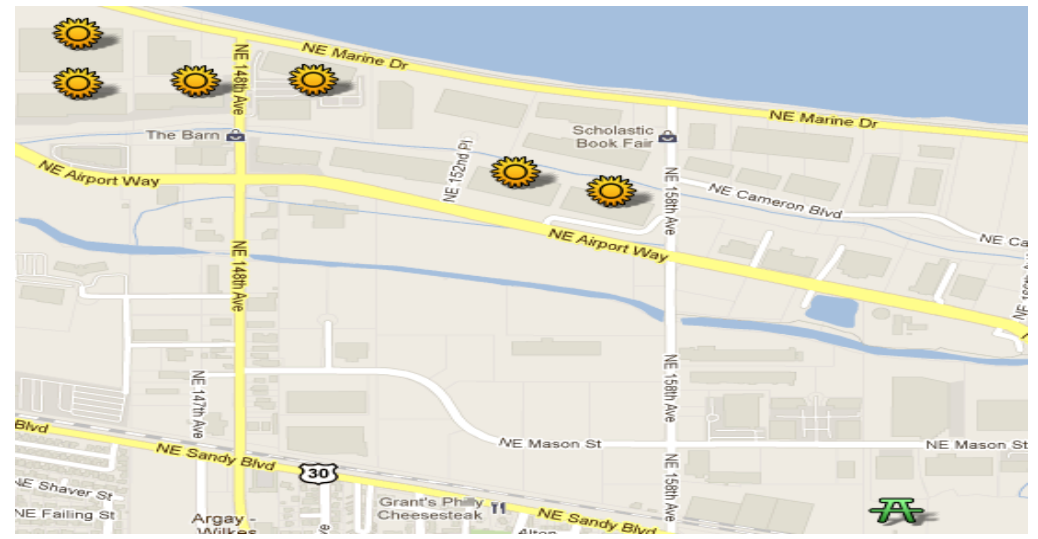

Figure 3-3 The selected feeder location

The feeder selected for the PGE SEGIS project is located along the Columbia River in North Portland (Oregon), which is close to Portland International Airport (Figure 3-3). When compared to the southern U.S., Portland's higher latitude and high annual rain fall yield lower solar radiation. Figure 3-4 shows the solar energy potential map across U.S. Portland is in the area of approximate $336-362$ watt hours/ft ${ }^{2}$ per day. 


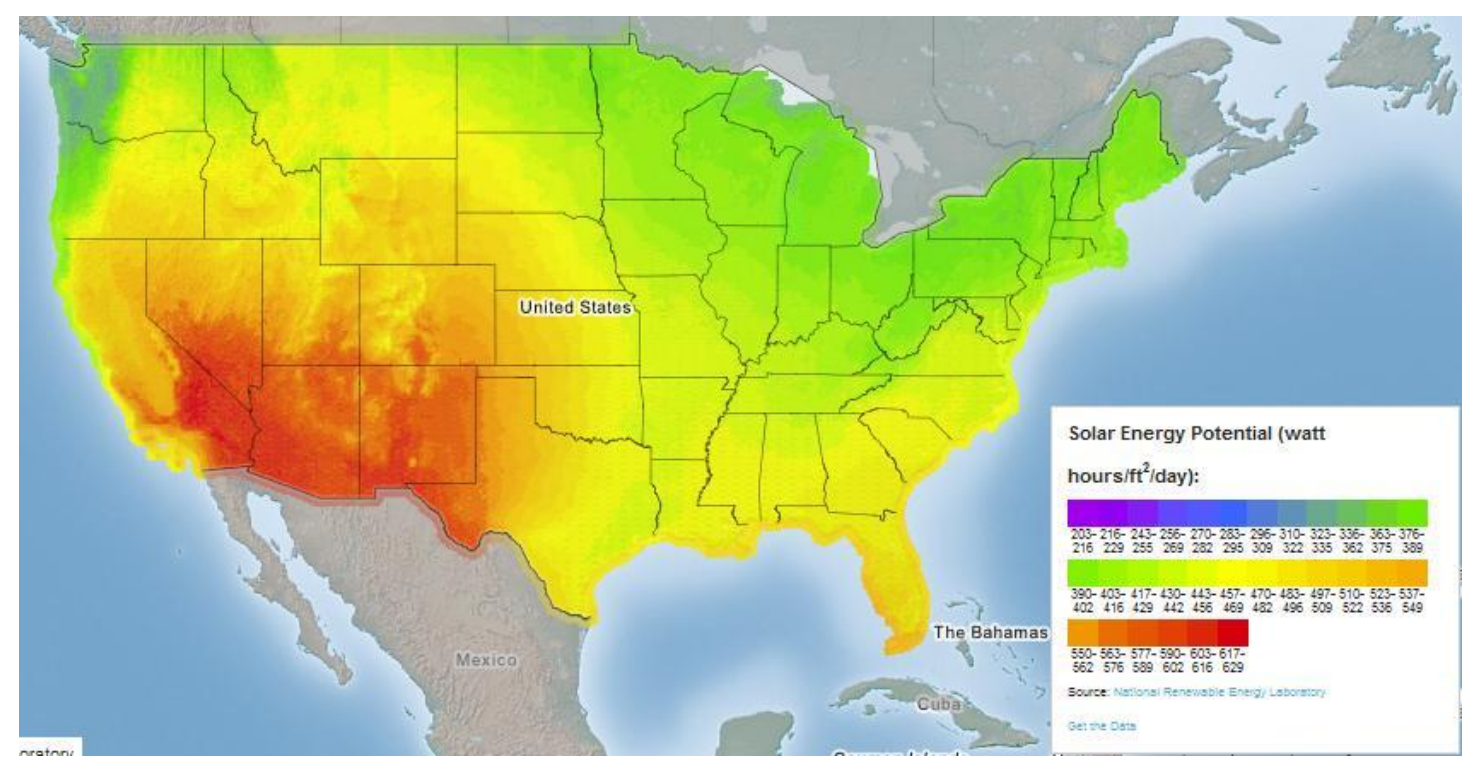

Figure 3-4 Solar energy potential in U.S. [38]

The summer season in Portland is pleasant not only with a comfortable temperature but a whole season of nice sunny days. Figure 3-5 is the amount of power generation $(\mathrm{kWh})$ of the PV system on the feeder for 2010. As expected, power generated in the summer season (Jun.-Aug.) acquired approximately 50\% of the whole year's generation profile.

2010 Yearly Power Generation

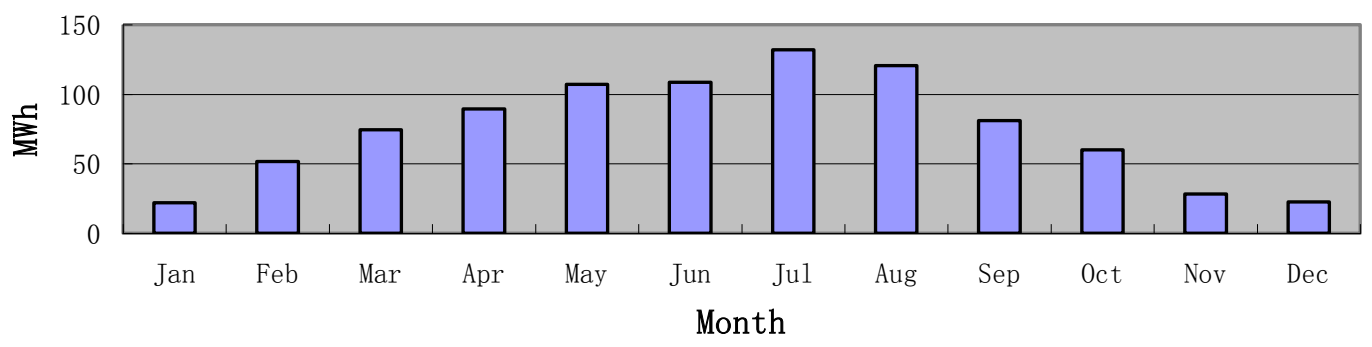

Figure 3-5 PV generation amount of the feeder for Jul, 2010-Jun,2011 


\subsubsection{PV Generation Performance on the Feeder}

The previous section presents a whole year's electricity generation on the feeder according to the radiation flux. In this section, we discuss performance of the PV day generation based on various load conditions.

Since the loads on the selected feeder are mainly commercial, as illustrated in Figure $3-6 \mathrm{a}$, the peak period of a workday is 8 am to $4 \mathrm{pm}$. There is no peak period during weekend or holidays. Thus feeder load is close to flat (Figure 3-6b). As described in the last section, power generation in different seasons will have various effects on the feeder load.

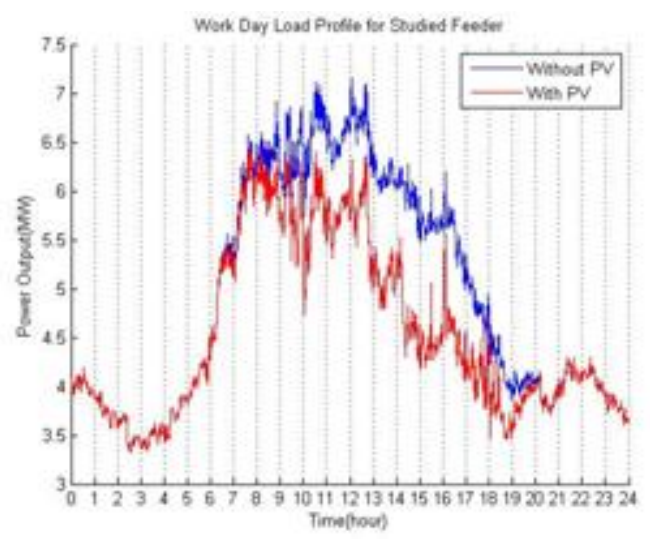

(a)

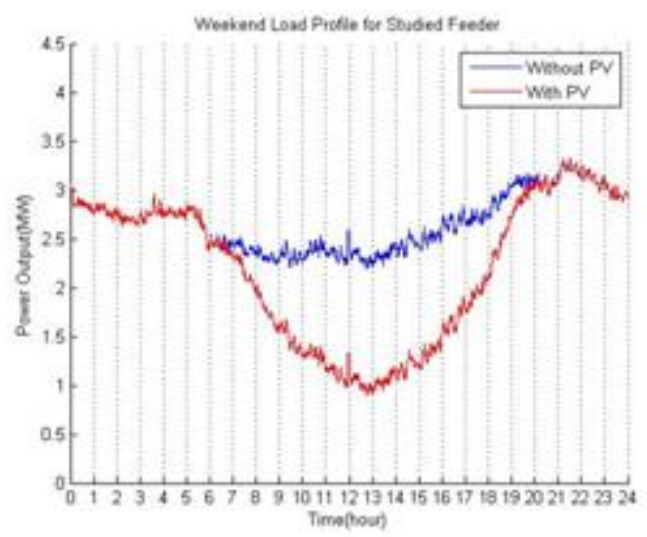

(b)

Figure 3-6 (a) Weekday load profile of the studied feeder (b) Weekend load profile of the studied feeder

It is forward straight to assess that the penetration rate is in the range of $10 \%-60 \%$ depending on the time. In particular, the electricity generated by PV systems met the entire feeder load demand for a brief period on a Sunday afternoon, which means the whole feeder was energized by pure PV power (Figure 3-7). Although this period is less than 2 minutes, we are able to predict that PV generation will definitely be an option for the replacements of traditional fossil energy resource and play as a significant role in 
renewable energy era.
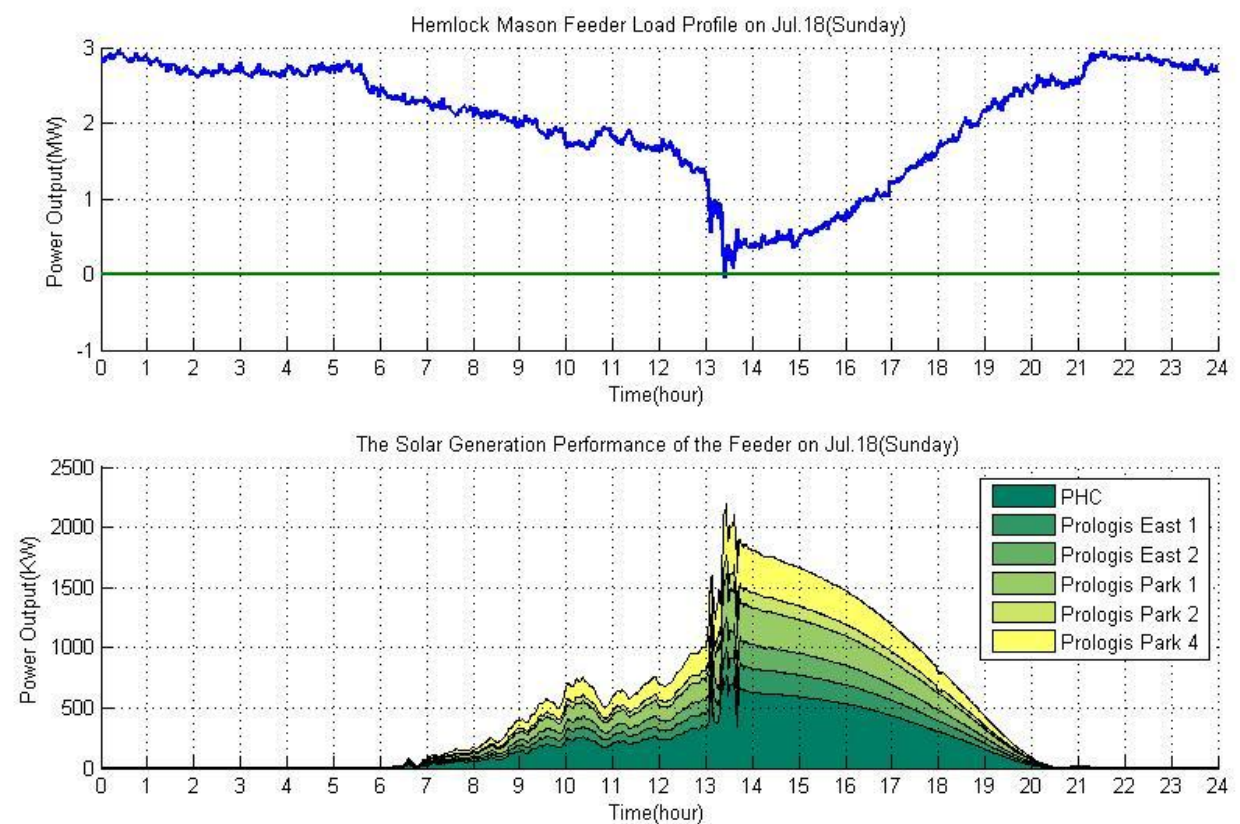

Figure 3-7 Load profile and PV generation on the maximum PV production day

\subsection{Voltage Impact of PV Generation of the Feeder}

The literature indicates clearly that integrated DG could impact the voltage of the distribution grid [13]-[18]. For the selected feeder, however, the voltage measured at the substation end is stable even in the condition where the whole feeder was supported by PV generation as described above. The fluctuation range is $\pm 1 \%$, as shown in Figure 3-8. Reference [19] pointed out that in the event that the DG produces more power than the local demand, the net power will flow upstream (towards the substation). If this reverse flow is sufficiently large, it will overcome the voltage drop caused by the reactive power flow and may result in an over voltage at the energy connection point (ECP). Since all PV systems on the studied feeder first energize the local load with very small surplus power; the continuous time is short, and the impact to the grid voltage can be neglected in this 
case (Figure 3-9). Nevertheless, the voltage could be affected if the $30 \%$ PV penetration feeder was in an area with high solar energy potential such as south California, Arizona, or New Mexico as shown in Figure 3-5. In this case, utilities may have to consider the effect that PV generation causes to the feeder. Those effects could impact the feeder voltage so that it could go over or under the bounds, which is not accepted by utilities. As a result, they could meet a bottle neck to approach their RPS. Utilities in Portland, on the other side, even in Oregon, can develop their PV sites on any feeder up to $30 \%$ penetration without worries. It will not only benefit utilities but also benefits the public with more job offering and more financial incentives from federal, state, and utility sources etc. (Figure 3-10)

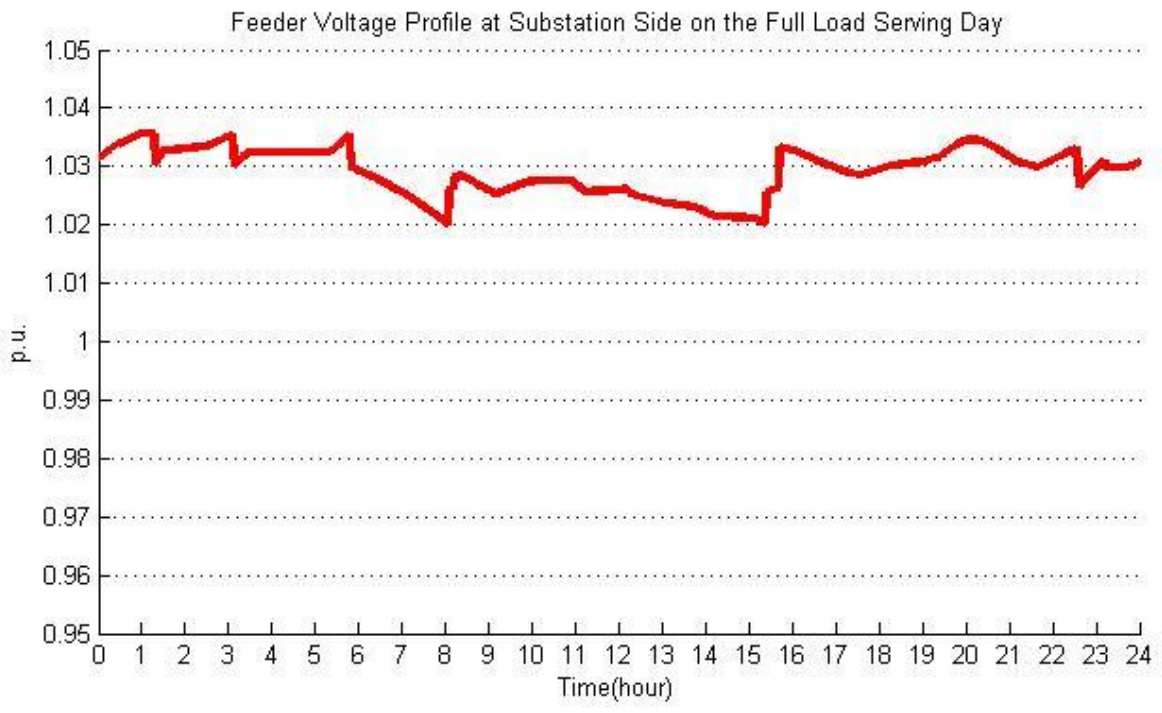

Figure 3-8 Feeder voltage profile 


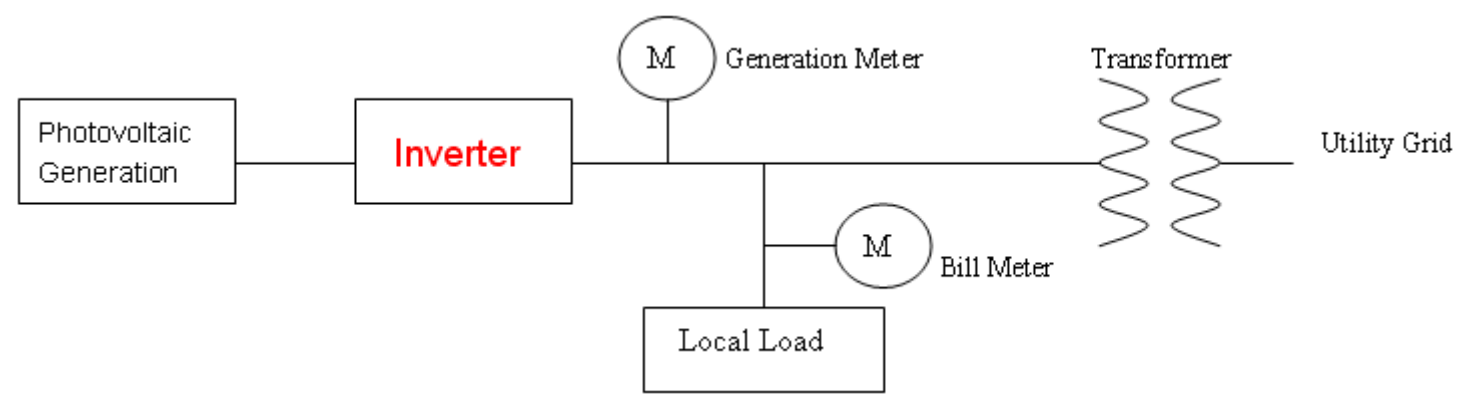

Figure 3-9 PV system structure for SEGIS

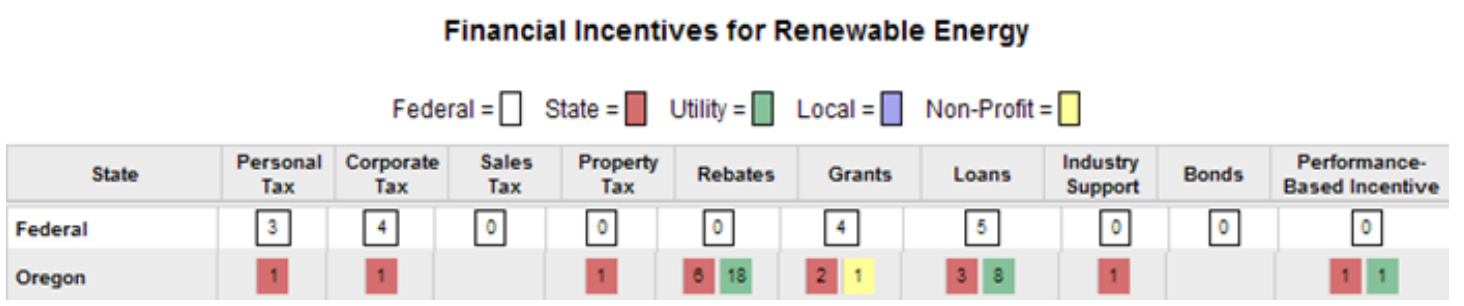

Figure 3-10 Financial incentives for renewable energy from Federal and Oregon

On the other side, an on-load tap changer (OLTC) at the $115 \mathrm{kV} / 13 \mathrm{kV}$ bus transformer (Figure 2-4) in the substation also regulates the feeder voltage. A transformer tap is a connection point along a transformer winding that allows a certain number of turns to be selected [37]. Thus, a transformer with a variable turns ratio is produced, enabling voltage regulation of the output. Figure 3-11 shows the OLTC with reactive power profile on the substation primary wire for five work days. The $115 \mathrm{kV} / 13 \mathrm{kV}$ bus transformer in the substation has \pm 7 turns of taps to be selected. The LTC changes the selector to respond the changing VAR consumed on the feeder. However, there is a limit of the voltage range that an OLTC can tune in the case of DGs interconnection. Plus, with the expected growth proportion of PV penetration, the power from DGs also impacts the voltage of a distribution grid, especially in rapid radiation changing days due to cloud movement, so that the OLTC may not respond in a timely manner. Currently, according to IEEE 1547, all DGs are expected to operate at a power factor of at least $85 \%$ (lead or lag) 
[20]. IEC 61850-7-420 specifies that VAR control mode is an essential function for the coming new generation of smart inverters [21]. In another word, if the reactive power can be controlled and adjusted intentionally, the feeder voltage can be stabilized by VAR controlling. More details about power factor control and grid support function will be introduced in Chapter 5.

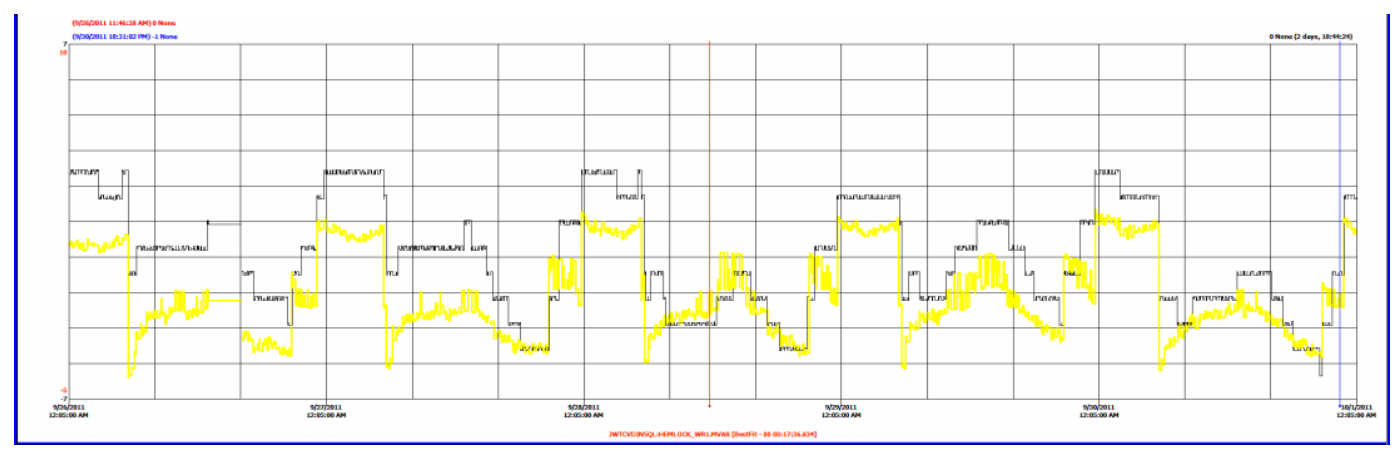

Figure 3-11 OLTC reaction with VAR changing

\subsection{Summary}

This chapter introduced the SCADA system developed by PGE for monitoring and analyzing DGs status and performance. It summarized one year of PV generation on the SEGIS project selected feeder, which shows the best production season in Portland. It is also verified that the selected feeder has the potential to be a high-penetration feeder during sunny summer weekends with a load plot produced by MATLAB. Then the feeder voltage on that day was analyzed and a result that the feeder voltage was not impacted by $\mathrm{PV}$ generation was shown. Therefore, it is verified that the $30 \% \mathrm{PV}$ penetration is safe for feeder voltage in the weather condition of Portland. 


\section{Chapter 4 Island Detection with Synchrophasor (See Appendix)}

This chapter is presented in the Appendix, since the author did not contribute to the technical content. It discusses about a new islanding detection method based on synchrophasor. It first gives the definition of an island and then introduces intentional and unintentional islanding. Second, it presents the conventional islanding detection method such as passive and active methods, communication methods and compares them to the synchrophasor method. It then explains the theory, followed by the simulation with EMTP and RTDS. Finally, a live demonstration is presented to show how well the method works. 


\section{Chapter 5 SEGIS Project for Grid Support and Micro-grid Operation}

High penetration of PV comes with more critical requirements for smart control of the distribution grid. The uncertainty and fluctuating output of a PV system due to the weather will impact the distribution grid significantly, and could even cause a blackout. An added energy storage system, which may reduce the impact of these conditions, is currently too costly to implement in a large scale manner. The SEGIS project has been developing technology to deal with these events which include, micro-grid operation, over-voltage and under voltage control.

\subsection{Micro-grid Operation}

The synchrophasor-based islanding detection method described in Chapter 4 is one of the major subjects of SEGIS. The purpose of this method is not only to avoid an island under current standard, but also to run the intentional island in a high-penetration DG network. The significance of the term "micro-grid" which was proposed in the "SEGIS Program Concept Paper" [7]is that in the condition of an outage or blackout, DGs in the micro-grid can still energize all loads in it. The operation of the micro-grid is an intentional islanding. A micro-grid can increase grid reliability and energy security by providing utilities with local power generation (e.g. distributed PV system) and backup storage. Enabling a portion of the distribution grid and critical facilities to operate independently from the larger grid necessarily reduces power outages and improves power reliability for customers. Smart micro-grids allow utilities to increase the overall 
electricity supply quickly and efficiently through distributed generators. An example of PV smart micro-grid system operation is described as follows.

In a neighborhood of some homes connected to a smart-micro grid, all of these homes have installed distributed PV systems and are generating electricity to the distribution grid. Suddenly, a power outage happens. The smart micro grid instantaneously disconnects from the grid and powers the homes connected to it. If the total output power is higher than the total load, the surplus power will energize a backup storage system or be curtailed by smart control. On the other side, the storage system will be initialized to support the load of the micro-grid. However, the load could increase even with the storage support, thus the micro-grid cannot support the full load. In this case, certain loads automatically get turned off in a pre-planned priority order, to prioritize some critical loads such as a hospital. When the power on the grid is restored, the smart micro-grid will automatically sync back the distribution grid and reconnect. This process can be achieved by PMU equipments which take advantage of synchrophasor technology to facilitate the smooth detection and transitions back to the grid of the islanded section.

\subsection{Grid support Function}

Because of the high penetration DG generation in an micro-grid, the DGs should be capable of supporting the voltage of the distribution network in either islanding operation or grid-tied operation. In another word, DGs should have the function of voltage stabilization. As presented at the beginning of this chapter, this function is more important in a high penetration PV micro-grid. It is regulates that the new generation 
inverter must be capable of controlling the VAR output and curtailing the power output. In this section, two examples will be shown to explain how the two functions regulate the voltage in a high penetration PV distribution network.

\subsubsection{Over-voltage Mitigation}

All PV owners like sunny days, which means their PV system can generate more power for them to make benefits of energy sales. In a high PV penetration distribution feeder, however, this could cause adverse conditions which could negatively impact both utilities and customers.

On a very high solar PV penetration feeder, the load on the feeder is low and when the sun suddenly comes up and becomes bright, the solar output rises significantly and quickly. The distribution feeder experiences a quick over-voltage. Traditional utility equipment often does not have time to react to such a quick and unexpected increase in voltage. Electrical equipment such as air conditioners, appliances and lighting will run in an inefficient level and their useful life will be shortened due to high voltage. An electric bill or increased maintenance cost could be high for a business or a home that regularly experiences higher voltage level. (Figure 5-1) In the case of a severe over-voltage, voltage exceeds the equipment ratings, instantaneous equipment failure can occur. Over

time, if such conditions persist, the local utility may feel the need to limit the amount of renewable solar power that could be tied to a distribution feeder in order to prevent these voltage fluctuations, due to high penetrations of solar PV. 


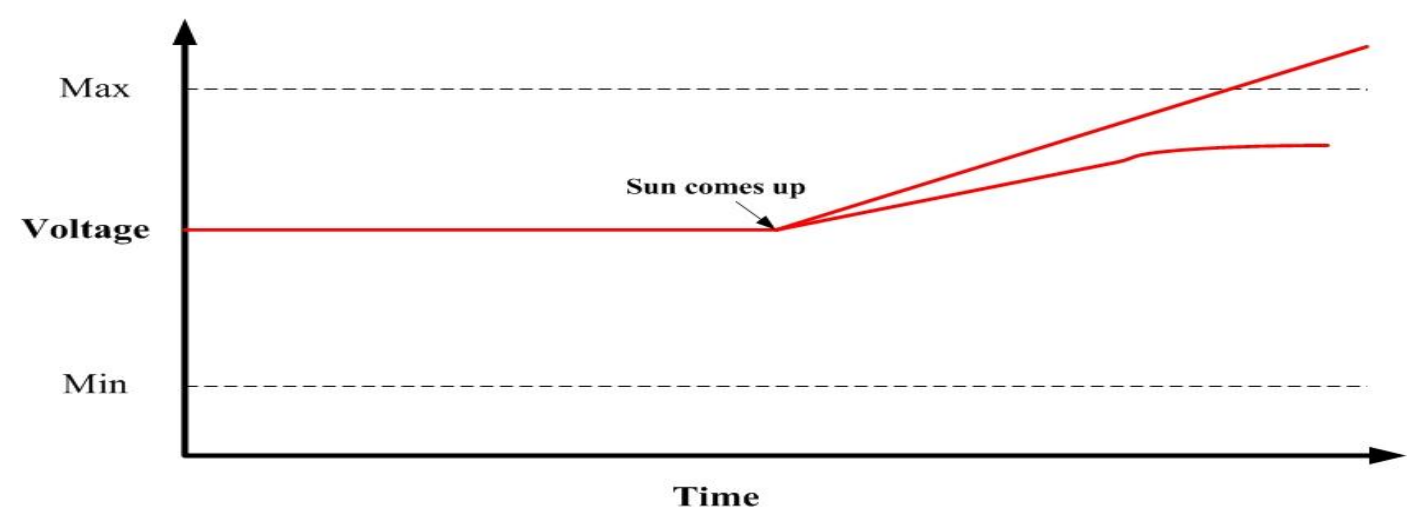

Figure 5-1 Overvoltage due to high penetration of PV

By the developing an over-voltage control scheme, the over-voltage can be limited by utilizing the VAR mode of the inverter. When the voltage increases on the feeder, the VAR mode control scheme could dynamically respond by tuning the power factor to sink reactive power as needed to mitigate the voltage above the desired level. (Figure 5-2)

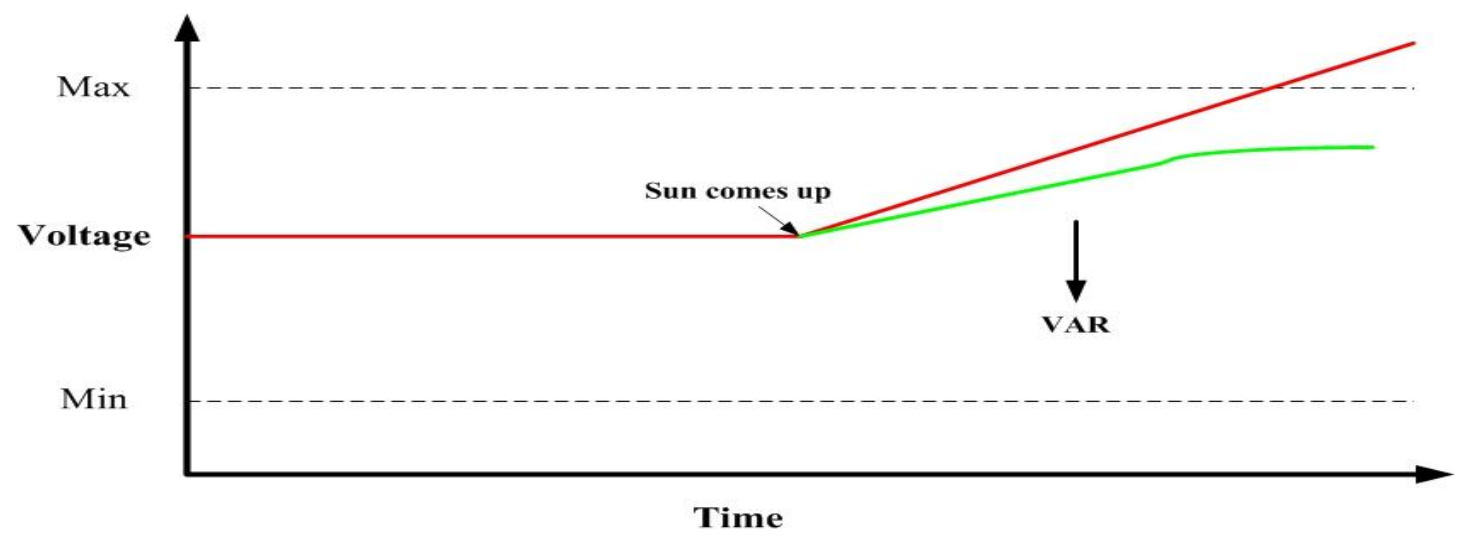

Figure 5-2 VAR mode control to mitigate over-voltage

In some instances, unfortunately, the voltage is not sufficiently lowered by sinking VAR only. In that case, the power generated by PV systems will be automatically cut back. Power curtailment is another feature that helps maintain grid stability. (Figure 5-3) 


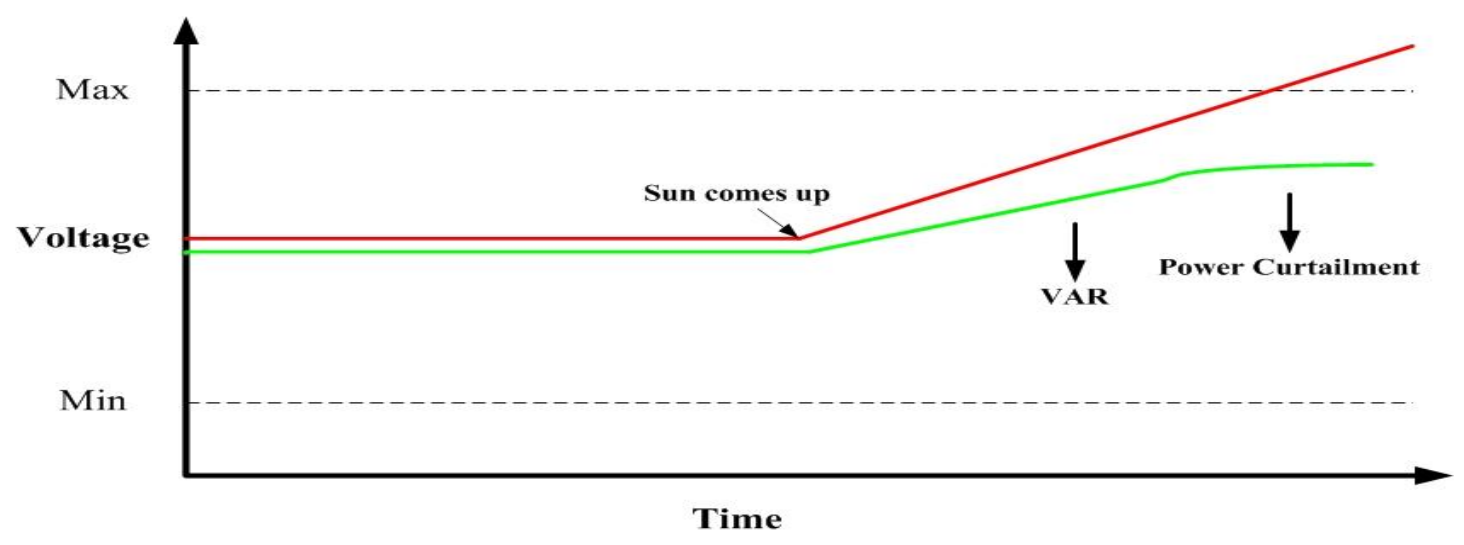

Figure 5-3 VAR mode control and Power Curtailment to mitigate over-voltage

\subsubsection{Under-voltage Mitigation}

On the other hand, an under-voltage condition on a feeder due to high penetration is not expected either.

On the same high penetration feeder as we assumed in the last section, the load is high due to a hot day. At the beginning, the day is sunny and the PV output is high. A cloud rolls in quickly and the solar output drops as quickly and significantly. When the solar drops, the load on the feeder jumps to a high level, thus the feeder experiences a quick under-voltage. Traditional utility equipment often does not have time to react to such a sudden unexpected drop in voltage. Low voltage condition can lead to voltage sags or power outages. Outages cost utilities money (Figure 5-4) with the same consequences as an over-voltage. Over time, if the condition persists, the local utility may feel the need to the need to limit the amount of solar power that could be tied to their electric grid in order to prevent this voltage fluctuation due to high-penetration of solar PV. 


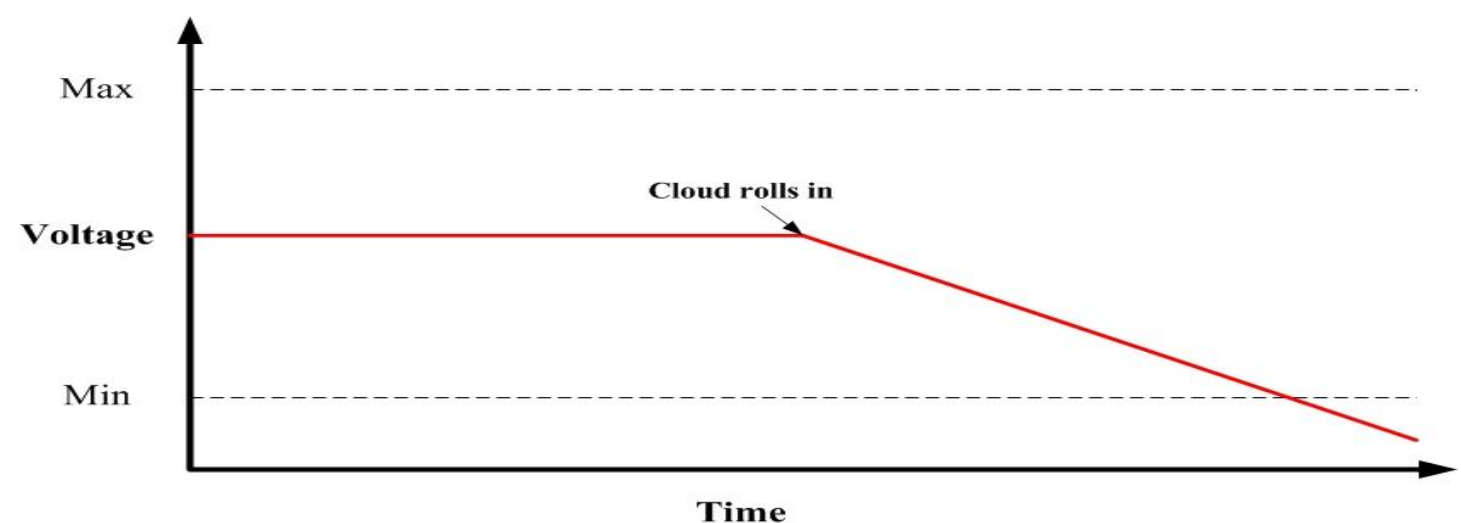

Figure 5-4 Under-voltage due to high penetration of PV

With the developing under-voltage control scheme, the inverters of a PV system can dynamically respond by sourcing reactive power as needed to mitigate sags of voltage below the desired level. The result is that households do not experience outages and the utility is not forced to limit solar power on its grid. (Figure 5-5)

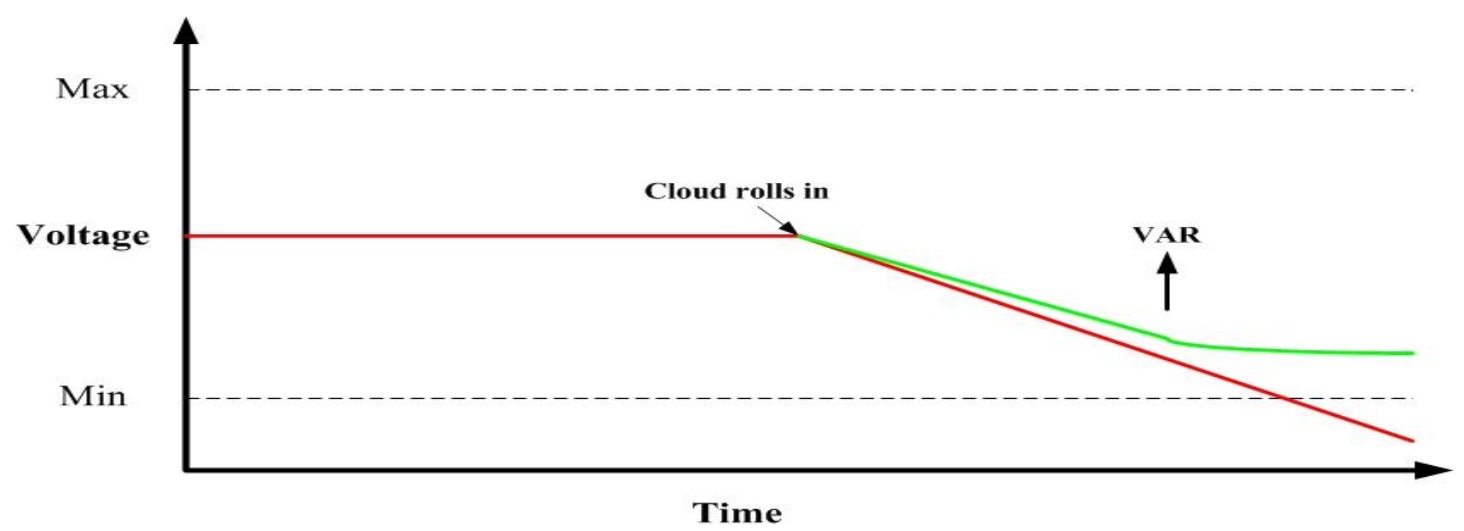

Figure 5-5 VAR mode control to mitigate under-voltage

\subsection{Summary}

This chapter presented micro-grid operation in a high penetration PV condition and the grid support function of next generation inverters. It described the micro-grid concept and grid support function in the SEGIS concept paper [7] with examples to show how the future high-penetration PV reaches these requirements. Certainly, to realize these 
functions, these technologies must be combined with other systems such as communication systems, energy management system and SCADA system as described in that paper. 


\section{Chapter 6 Concluding Remarks}

The SEGIS Phase III project was completed successfully with PGE, Advanced Energy, SEL, NPPT and SNL. This thesis discusses the main achievements that PGE obtained as one of the partners.

\subsection{Summary and Conclusion}

First, this thesis introduces all commercial distributed solar PV system that PGE has built between 2003 and 2010. These systems helped PGE to have the largest rooftop distributed PV systems in Oregon. Because of this success, PGE was picked as a partner of SEGIS project based on its initial success with PV system to help solve a series of problems in distributed solar PV systems. This led to the current task was proposed to enhance the ability of high penetration PV feeders for on low-voltage ride through, accurate and economical islanding detection, and voltage stabilization was proposed.

Second, the thesis introduced the self-developed SCADA system, GenOnSys, as the main tool for system observation and monitoring, and data collection for the SEGIS project. With this SCADA system, the thesis analyzed the yearly performance of the feeder which was selected for the SEGIS project and verified that the feeder has the potential to support the whole feeder's load. It compared the voltage profile on the full load support day and analyzed the reason for how the voltage was kept stable. As a result, it concluded that the VAR control is an essential function in future high PV penetration system.

Third, the thesis described different traditional islanding detection methods and 
proposed the one with synchrophasor-based technology for additional study. The synchronphasor-based islanding detection method has the low-voltage ride through ability depending on its restrain region and a time "buffer" before an island is captured. A laboratory test ${ }^{*}$ and a live demonstration were performed at a PGE site was performed and discussed in the thesis. Both of them obtain results close to the consequences, as expected outcomes.

Last but not least, the thesis envisioned the characteristics of future smart micro-grid operations and applications. It also described how the VAR control mode supports the grid to stabilize the voltage in a high PV penetration distribution network.

\subsection{Future Research}

As described in the Appendix, research in a more accurate restrain region is required for diverse distributed renewable generation. To stabilize the voltage dynamically, a corresponding algorithm is also needed to control sinking or sourcing reactive power from or to the grid. For future smart micro-grid and smart grid operation, an economical and reliable storage system is absolutely necessary in the SEGIS or any other distributed renewable generation to ensure backup storage. As described in the SEGIS concept paper [7], a more advanced energy management system is required for the intermittent solar resource. Certainly, the development of control and secure communication for internal and external data transfer are essential and need to be developed for future SEGIS.

PV generation is a fairly mature renewable generation technologies but has much opportunity to improve in efficiencies and cost reduction. We believe that humans should

\footnotetext{
* The lab simulation result of synchrophasor are performed by Advance Energy and NPPT in SEGIS team, which is described in the Appendix
} 
be able to use light, which was first created by God, to not only brighten our lives, but to power our future. 


\section{Reference}

[1] Eva Wissenz, "The Principles of Solar Concentration", http://www.solarfire.org/The-Principles-of-Solar

[2] Picture from Wikipedia: http://en.wikipedia.org/wiki/File:Available Energy-4.png

[3] Picture from Wikipedia: http://www.ez2c.de/ml/solar_land_area/

[4] European Commission, Joint Research Centre, Institute for Energy, "PV Status Report 2008"

[5] Chihheng Liang, Sophia Chen, "China PV Industry Development, by region", DIGITIMES Research, November 2011

[6] Chihheng Liang, "The Role of PV in China's Energy Policy through 2015", DIGITIMES Research, October 2011

[7] U.S. Department of Energy, Sandia National Lab, "Solar Energy Grid Integration System 'SEGIS'-Program Concept Paper”, Oct.2007

[8] U.S. Department of Energy Website: www.doe.com

[9] Mesa Scharf, Michael Mills-Price, "Laying the Foundation for the Grid-Tied Smart Inverter of the Future

[10]"Sun Shines Bright for This Oregon Food Processor", FIRE Industry Resource Efficiency

[11] "PGE ranks among highest in nation in solar power generation - Solar Electric Power Association ranks PGE in top 10 utilities", PGE News Room, May,28, 2009

[12]Mark Osborn, "Solar to Grid", Transmission and Distribution World, Apr. 1, 2011

[13]Philip P. Barker, Robert W. de Mello, "Determining the Impact of Distributed Generation on Power System", Volume 3, Power Engineering Society Summer Meeting, 2000. IEEE

[14]Juan A. Martinez- Velasco, Jacinto Martin- Arnedo, "Distributed Generation Impact on Voltage Sags in Distribution Networks", Electrical Power Quality and Utilisation, 2007. EPQU 2007. $9^{\text {th }}$ International Conference

[15]Math H.J. Bollen, Mats Hager, "Impact of Increasing Penetration of Distributed Generation on the Number of Voltage Dips Experienced by End - Customers", Electricity Distribution, 2005. CIRED 2005. $18^{\text {th }}$ International Conference and Exhibition

[16]Y. Liu, J. Bebic "Distribution System Voltage Performance Analysis for High-Penetration PV", NREL/SR-581-42298, February 2008

[17]L. Kojovic, "Impact of DG on Voltage Regulation", Proc. IEEE/PES Summer Meeting Chicago, IL, July 21-25, 2002

[18]R. Claire, N. Retiere, S. Martino, C. Andrieu, N. Hadjsaid "Impact Assessment of LV Distributed Generation on MV Distribution Network", Proc. IEEE/PES Summer Meeting, Chicago, IL, July 21-25, 2002

[19]Yahia Baghzouz, "Voltage Regulation and Overcurrent Protection Issues in Distribution Feeders with Distributed Generation - A Case Study", $38^{\text {th }}$ Hawaii International Conference on System Sciences, 2005

[20]E.Tom Jauch, "Possible Effects of Smart Grid Functions on LTC Transformers", 
IEEE transactions on industry applications, vol. 47, No. 2, Mar/Arp, 2011

[21]Specification for Smart Inverter Interactions with the Electric Grid Using International Electrotechnical Commission 61850

[22] "IEEE Recommended Practice for Utility Interface of Photovoltaic (PV) Systems", IEEE standard 929, 2000

[23]H.Zeineldin, E.F.El-Saadany, M.M.A.Salama "Intentional Islanding of Distributed Generation”, 1496 - 1502 Vol.2, Power Engineering Society General Meeting, 2005. IEEE

[24]K. Nigm, and Y. Hegazy, "Intentional Islanding of Distributed Generation for Reliability Enhancement", IEEE Power Engineering Society General Meeting, pp. 208-213 Oct. 2003.

[25]F. Pilo, G.. Celli, "Improvement of Reliability in Active Networks with Intentional Islanding”, IEEE International Conference on Electric Utility Deregulation, Restructuring, and Power Technologies, pp. 474-479, April 2004.

[26]P. Power, F. Castro-Sayas, "The Cost and Benefits of Embedded Generation Islanding Operation", Report Number: k/EL/00284/REP, 2002.

[27]R. A. Walling, Senior Member, IEEE, and N. W. Miller, "Distributed Generation Islanding - Implications on Power System Dynamic Performance." Proceedings of the IEEE/PES Summer Power Meeting, Chicago, July, 2002.

[28]Chongxuan Niu, "Micro-grid Islanding Detection and Island Partition", Master degree thesis, Tianjing University, 2008

[29]IEEE Std. 1547-2003

[30]IEA PVPS, "Evaluation of Islanding Detection Methods for Photovoltaic Utiity interactive power system", Report IEA PVPS T5-09:2002. www.iea.org. September 7, 2006

[31]Wikipedia: http://en.wikipedia.org/wiki/Synchrophasor

[32]Michael Mills-Price, Mesa Scharf, Michael Ropp, etc. "Interconnection Control of Distributed Generation With Time-Synchronized Phasors", Power Systems Conference and Exposition (PSCE), 2011 IEEE/PES

[33] "Interim Report of the Investigation Committee on the 28 September 2003 blackout in Italy," Union for the Coordination of Electricity Transmission, p.59, October 2003.

[34]E. O. Schweitzer, III, D. E. Whitehead, G. Zweigle, and K. G. Ravikumar, "Synchrophasor-Based Power System Protection and Control Applications," proceedings of the 36th Annual Western Protective Relay Conference, Spokane, WA, October 2009.

[35]J. Mulhausen, J. Schaefer, M. Mynam, A. Guzmán, and M. Donolo, “Anti-Islanding Today, Successful Islanding in the Future," proceedings of the 36th Annual Western Protective Relay Conference, Spokane, WA,October 2009.

[36]"Portland General Electric Wins National Solar Business Achievement Award", Business Wire, Oct. 8, 2009

[37]The definition of tap transformer: http://en.wikipedia.org/wiki/Tap_(transformer)

[38]National Renewable Energy Laboratory (NREL) website: www.nrel.gov 


\section{Appendix Island Detection with Synchrophasor}

Islanding detection is one of the essential issues to consider in distributed generation systems. This Appendix provides a brief introduction on island definition, current standards and conventional islanding detection methods. Compared to the proposed islanding detection method, which is based on synchrophasor technology, conventional detection methods, which are based on the voltage, frequency, and phase at the ECP, have disadvantages. These conventional methods can meet current requirements of islanding detection, but the detection speed and accuracy for islanding detection is becoming more critical as the distributed systems connected to the grid increases. The SEGIS project demonstrated the synchrophasor detection method and showed its outstanding advantages on accuracy and ride-through ability.

\section{Islanding}

\subsection{Island and Islanding Effect}

Islanding is "A condition in which a portion of the utility system that contains both load and distributed resources remains energized while isolated from the remainder of the utility system" [22]. In the power system, an island means a self-powered distribution network with DG and loads which is independent from the utility grid. Zone 1, Zone 2, Zone 3 in Figure A-1 are islands in different areas due to break tripping positions. Islands may be caused by feeder faults, frequency/voltage over limitation and oscillation. According to the mismatch between the load and power from DGs in an island, it could 
either run below stable or experience an outage after being disconnected from the utility. Generally, the power sourcing and sinking in an island will lose balance as soon as it is disconnected from the distribution grid if the total power from DGs is less than the total loads in the island. On the another hand, however, an island is able to operate steadily if total power offering is equal to or larger than total load in the island, island effect or "islanding".

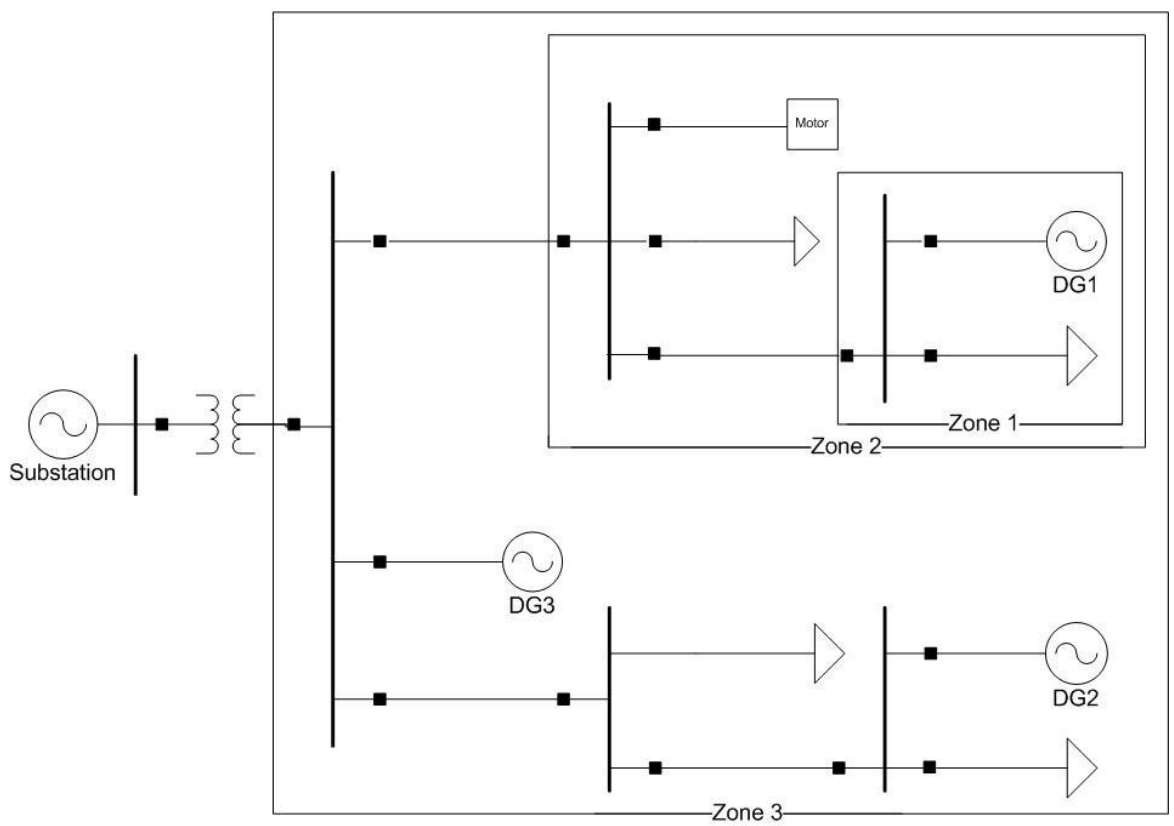

Figure A-1 Islanding illustration

\subsection{Intentional Islanding and Unintentional Islanding}

\section{1) Intentional Islanding [23]}

In intentional islanding, an island operating section is planned in advance according to the DG size, system status before faults, and total local loads so the isolated system is able to run steadily after disconnecting from grid. Intentional islanding can improve the quality of supply indices and reliability [24] [25]. Aside from that, additional revenue to DG owners can be achieved due to the increased power supplied during network outage. 
Their DGs are able to support the neighborhood according to their capacities and owners receive payment from the utility. Customer satisfaction can also increase due to the reduction of the frequency and duration of interruptions from outages in the distribution network [26].

\section{2) Unintentional Islanding}

Unintentional islanding occurs when a portion of the distribution system becomes electrically isolated from the remainder of the power system, yet continues to be energized by the DG connection to the isolated subsystem [27]. Unintentional islanding is unpredictable, happens occasionally, is unplanned, and may operate under uncertain range. All of which will lead to a series of safety problems to power system:

a) It can not be determined whether DG continue to supply power to feeders since unintentional islanding is unpredictable and the territory is uncertain. The safety of the utility linemen is threatened because of power being supplied to the load side of disconnects and downed power lines.

b) If the power mismatch between DG and load exists in the island, it will cause voltage or frequency fluctuation or over/under limitation, reduced power quality and damage utility to and customers devices.

c) The changing of the current through protection systems could bring unexpected action of the protection device.

d) Impact on reconnection: Utility protection relays are designed to detect a fault. Reclosers briefly disconnect power from the area around fault to allow the fault to clear, and then reconnect to provide continuing service. If islanding detection failed 
and DGs remain on-line, the reconnection could fail and damage could happen to relay and DG equipment.

To avoid danger and damage caused by unintentional islanding, most grid-connected DGs are required to have anti-islanding mechanism to protect the system when unintentional islanding happens. The current solution is to shut the DG off and disconnect it from grid in a short period. According to IEEE Std.1547-2003, the anti-islanding strategy should be executed within 2 seconds.

\subsection{Anti-islanding Strategy and Utilizing Islanding [28]}

Because of the damage unintentional islanding may cause to power system, there are two points of view for dealing with islanding: anti-islanding and utilizing islanding.

Anti-islanding is a strategy made to forbid an island. This is important since islanding can lead to a series of negative impacts to the power system, and the danger is increasing with the growth of DG penetration in the grid. Therefore, IEEE Std. 999-2000 and UL171, the first constituted standards, regulate such that DG equipment must adapt anti-islanding strategies to prevent islanding. According to the standard, all ECP of DG units on the feeder where a fault happens must trip under any fault condition. If some DGs still remain connected to the grid and form islands with certain reasons, islanding detection equipment should detect and trip offline those DGs. However, the disadvantage of this strategy is reduced reliability. Also, DG generation ability can not be fully utilized. This not only causes economic loss to DGs owners and customers but departs from the initial intent of DG, which is to improve power supply reliability. 
To maximize the benefit of DG and enhance the capability of sourcing power, IEEE proposed a new standard - IEEE std.1547.2-2008, which provides technical background and application to support understanding IEEE std.1547-2003. It propagates rules to protect the electrical power system (EPS) from unintentional islanding and provides rules for testing the aggregate DG system. However, unlike the previous version, the new standard does not forbid all islanding but utilizes islanding operation as a new scheme to improve system reliability. Islanding utilization means forming an island based on a preset the control scheme. The DG system continues sourcing power to surrounding loads it can carry when an outage happens due to a fault or system maintenance, which could help to reduce the loss of outage, improve the quality of power supplying and reliability.

\section{Islanding Detection Methods}

Whether anti-islanding or utilizing islanding, islanding detection methods are always required for a PV integrated system. This section describes the current most popular international islanding detection standards, i.e. IEEE Std. 1547, and its main detection methods.

\subsection{Islanding Detection Standards [29]}

The IEEE Std. 1547 is applicable to a DG-unit with a rated power of less than 10MVA and connected to the primary or secondary distribution system. As the world's dominant standard for islanding detection, it is adopted by many of power utilities and inverter manufacturers. The IEEE Std. 1547-2003 states that an island shall be detected 
and de-energized within two seconds from the island formation. Table A-1 lists detail requirements on various conditions of voltage and frequency.

Table A-1 IEEE Std. 1547 Requirement for Islanding Detection

\begin{tabular}{|c|c|c|c|c|}
\hline Condition & Voltage(V) & Frequency(Hz) & Cycles & Time(s) \\
\hline A & $\mathrm{V}<0.5 V_{N}{ }^{1}$ & $f_{N}{ }^{2}$ & 6 & 0.1 \\
\hline $\mathrm{B}$ & $0.5 V_{N}<V<0.88 V_{N}$ & $f_{N}$ & 120 & 2 \\
\hline $\mathrm{C}$ & $0.88 V_{N} \leq V \leq 1.10 V_{N}$ & $f_{N}$ & No cessation & No cessation \\
\hline $\mathrm{D}$ & $1.10 V_{N} \leq V \leq 1.37 V_{N}$ & $f_{N}$ & 120 & 2 \\
\hline $\mathrm{E}$ & $1.37 V_{N} \leq V$ & $f_{N}$ & 2 & $2 / 60$ \\
\hline F & $V_{N}$ & $f<f_{N}-0.7 H z$ & 6 & 0.1 \\
\hline G & $V_{N}$ & $f>f_{N}+0.5 H z$ & 6 & 0.1 \\
\hline
\end{tabular}

1. $V_{N}$ is the nominal phase voltage (line to neutral)

2. $f_{N}$ is the nominal frequency of $60 \mathrm{~Hz}$

\subsection{Standalone Detection Methods}

The standalone detection method means an inverter based detection method, which includes passive detection methods and active detection methods.

Passive methods use locally available quantities such as voltage or frequency. When islanding occurs the utility loses control of voltage magnitude and frequency (VMF). The 
export/import of active power $\left(\Delta P_{\text {utility }}\right)$ and reactive power $\left(\Delta Q_{\text {utility }}\right)$ from the utility makes it possible to detect islanding for passive detection methods, due to excursions in VMF. The passive methods do not affect the waveform of the high voltage. This is beneficial since it does not give rise to power quality issues such as voltage sags. Another benefit is that there is no need to install more equipment except the inverter itself for detection so that there is cost-swing.

Nevertheless, in the case where load and generation are balanced, which includes no export/import of active and reactive power from the utility, the dependability of passive detection methods are not sufficient [30]. The so-called non-detection zone (NDZ) is much larger for passive than for active islanding detection methods (Figure A-2). Another problem for the passive detection method is the threshold value setting. The threshold must be beyond the VMF of normal operation and beneath the VMF of islanding. Since DG output power and the VMF of the grid may fluctuate when loads connect or disconnect, passive detection could trip the DG with the grid connected. Therefore, the methods are usually combined with active detection methods in today's islanding detection methods.

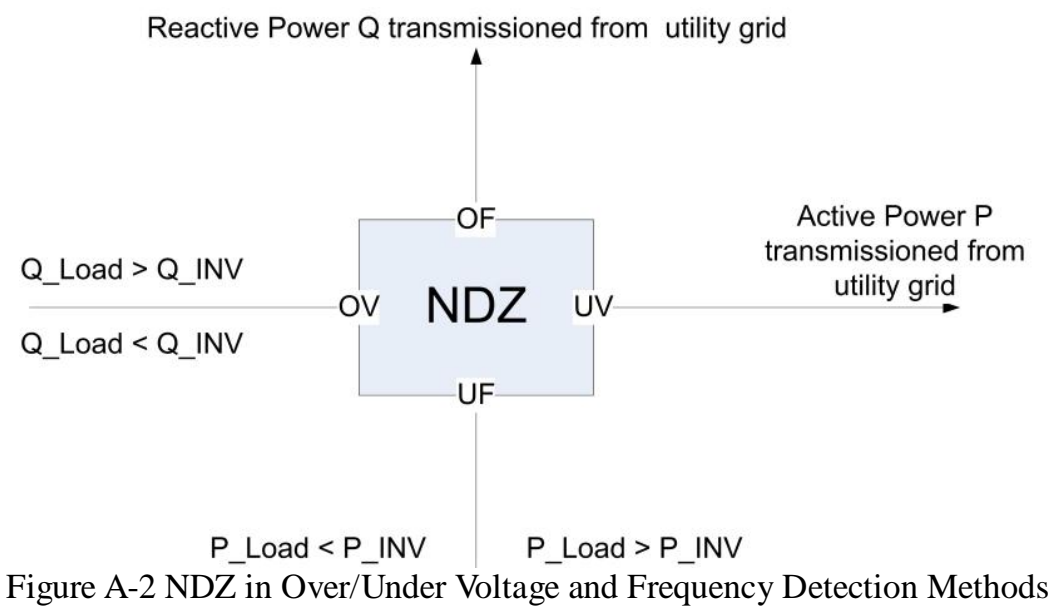


Active islanding detection methods inject a small disturbance signal on voltage, frequency or phase to inverter control signal to cause the measured parameters to be out of the normal operation range at the ECP in the islanding condition. Since the inverter is current controlled when parallel operating, the output current is:

$$
i_{i n v}=I_{i n v} \sin (\omega t+\phi) \quad \text { Eq.A-1 }
$$

There are three variables we can control to make the disturbance. Changing $I_{i n v}$ would disturb voltage; control $\omega$ effects frequency; manipulation of current and $\varphi$ impacts active and reactive power output. The disturbance is not obvious and will not trigger the islanding detection response when connected to the grid but it is very easy to observe as soon as islanding occurs.

However, the problem with the active detection methods is its negative effect on power quality due to perturbation. Typically, in multiple-inverter systems or high PV penetration distribution networks, these disturbances can lead to false islanding detection. Active detection methods may have less NDZ than passive ones but the problem that exists is to detect islanding in a timely manner and this is still difficult if the power (real and reactive) mismatch between the source and the local load is close.

\subsection{Communication Detection Methods}

Communication methods utilize breaker status communication, open-phase detectors, and trip commands to detect islanding and isolate the source. This transfer trip scheme is simple in concept but must be adapted to topology changes in the power system. As more PVs are connected to the system, reliability suffers because of the additional 
communications links. With this method, the only information available on the state of the distribution line between the inverter and the source is its connectivity, not signal magnitude and angle. Therefore, this method does not provide the information for future improvements where the inverter provides grid support functions.

Based on the above, existing standalone detection methods may have: 1) have power quality issues, 2) negative impact on system stability or 3) loss of effectiveness under high penetration and 4) very high cost. The current communication approach is costly and destabilizing at a high penetration level. Table A-2 compares alternative islanding detection methods, including the proposed synchrophasor method. Although the cost is currently higher than standalone detection methods, the advantage of the synchrophasor method is not limited to islanding detection but other control features such as dynamic adaptive VAR support, micro-grid, synchronized reclosing, and low- voltage ride through, which are essential features for a future high penetration inverter-based grid integration system.

Table A-2 Islanding Detection Alternative

\begin{tabular}{|c|c|c|c|c|c|}
\hline Technique & Safety & $\begin{array}{c}\text { Power } \\
\text { Quality }\end{array}$ & Advanced Feature & $\begin{array}{c}\text { Infrastructur } \\
\text { e Needs }\end{array}$ & Cost \\
\hline $\begin{array}{c}\text { Standalone } \\
\text { Methods }\end{array}$ & Good & Poor & Static VAR support & None & $\$$ \\
\hline $\begin{array}{c}\text { Power Line } \\
\text { Carrier }\end{array}$ & Very Good & No effect & VAR support, LVRT & $\begin{array}{c}\text { Power line } \\
\text { carrier signal } \\
\text { Modeling of } \\
\text { system } \\
\text { impedance }\end{array}$ & $\$ \$ \$$ \\
\hline $\begin{array}{c}\text { Transfer-Trip } \\
\text { Very good }\end{array}$ & No effect & VAR support, LVRT & $\begin{array}{c}\text { Fiber comm, } \\
\text { Relay/breaker } \\
\text { for } \\
\text { disconnect, } \\
\text { Known feeder } \\
\text { config }\end{array}$ & $\$ \$ \$ \$$ \\
\hline $\begin{array}{c}\text { Synchrophas-or } \\
\text { based detection }\end{array}$ & Very good & $\begin{array}{c}\text { Improves/ver } \\
\text { y good }\end{array}$ & $\begin{array}{c}\text { Dynamic adaptive VAR } \\
\text { support, microgrid, } \\
\text { synchronized reclosure, }\end{array}$ & $\begin{array}{c}\text { PMU data } \\
\text { comm. channel } \\
\text { Local PMU }\end{array}$ & \$ \\
\hline
\end{tabular}




\begin{tabular}{|l|l|l|l|l|l|}
\hline & & $\begin{array}{c}\text { LVRT, Enables smart } \\
\text { feeder operation }\end{array}$ & device & \\
\hline
\end{tabular}

\section{Synchrophasor-based Islanding Detection [32]}

The waveforms of alternating electricity were simplified with mathematical description by Charles Proteus Steinmetz's paper presented in 1893 . He called his presentation a phasor. A phasor is a complex number that represents both the magnitude and the phase angle of the sine waves found in electricity. Phasor measurements that occur at the same time are called "synchrophasors", as are the phasor measurement unit (PMU) devices that allow their measurement. In typical application phasor measurement units are sampled from widely dispersed locations in the power system network and synchronized from the common time source of a global positioning system (GPS) radio clock. Synchrophasor technology provides a tool for system operators and planners to measure the state of the electrical system and manage power quality. Synchrophasors measure voltages and currents at diverse locations on a power grid and can output accurately time-stamped voltage and current phasors. Because these phasors are truly synchronized, synchronized comparison of two quantities is possible, in near real time. These comparisons can be used to assess system conditions. [31] The synchrophasor-based islanding detection method takes advantage of this technology to detect an islanding in distributed grid integration system.

The synchrophasor-based islanding detection method overcomes the limitations of conventional methods presented above. The approach is not complicated to understand. Figure A-3 gives a brief concept of this synchrophasor-based detection for an 
inverter-based DG. The relays in Figure A-3 collect voltage phasor measurements from utility power system reference source (e.g. substation) and at local generators system respectively and send them to a synchrophasor vector processor (SVP) at a specific rate (e.g. 60 messages per second). The SVP calculates the difference between the local and remote synchrophasor angle values, which is defined as $\delta_{k}$ in (1):

$$
\delta_{k}=\angle V_{k}^{(1)}-\angle V_{k}^{(2)}
$$

where:

$\angle V_{k}^{(1)}$ and $\angle V_{k}^{(2)}$ are the positive-sequence voltage angles of Relay 1 and Relay 2 , at the $\mathrm{k}$ processing interval.

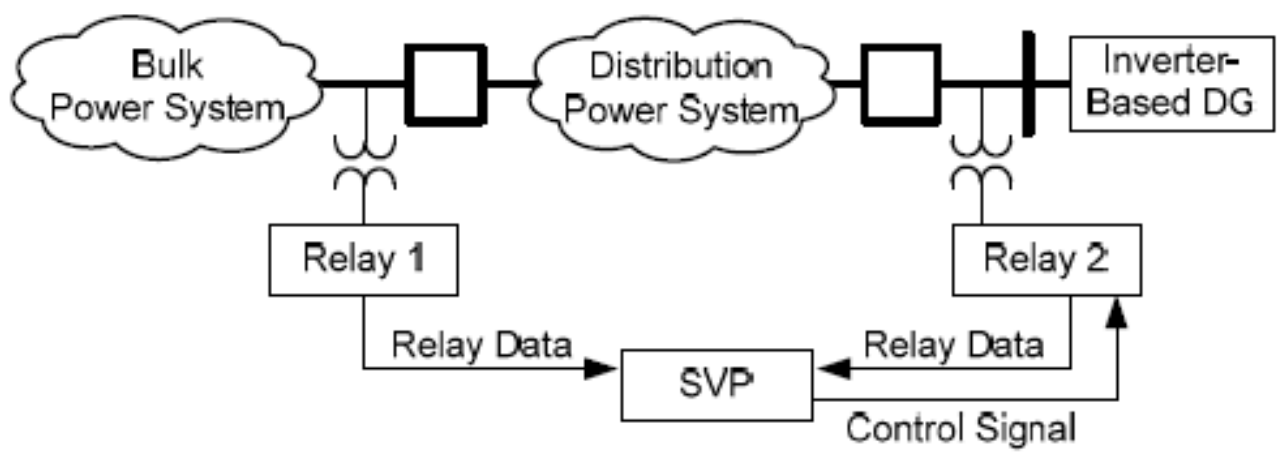

Figure A-3 Synchrophasor-based islanding detection system layout

The change of $\delta_{k}$, with respect to time, defines the slip frequency, $S_{k}$, and the change of slip frequency with respect to time defines the acceleration between the two terminals, $A_{k}$, are defined as follows:

$$
\begin{gathered}
S_{k}=\left(\delta_{k}-\delta_{k-1}\right) \frac{M R A T E}{360} \\
A_{k}=\left(S_{k}-S_{k-1}\right) M R A T E
\end{gathered}
$$

where: 
$S_{k}$ is the slip frequency at the k processing interval.

$A_{k}$ is the acceleration at the $\mathrm{k}$ processing interval.

MRATE is the synchrophasor message rate.

The islanding detection first compares the angle difference (1) to a threshold. For the islanded system, any slip between the local and remote systems results in a growing angle difference. In a short time, this steadily increasing change causes the angle to exceed the threshold. When the threshold is crossed for a preset time, an islanded condition is declared.

The second component combines slip and acceleration in a linear relationship. Figure A-4 shows the islanding detection characteristic. In steady state, slip and acceleration between the measured points are zero. When DG separates from the bulk power system, generally, there is both slip and acceleration. Either can push the operating quantity into the operate region of the characteristic. The linear relationship between the slip and acceleration characteristics results in an algorithm that operates for values below the individual thresholds when both are changing simultaneously. For example, if the acceleration and slip change by the same amount, the operate region enters along a diagonal path. 


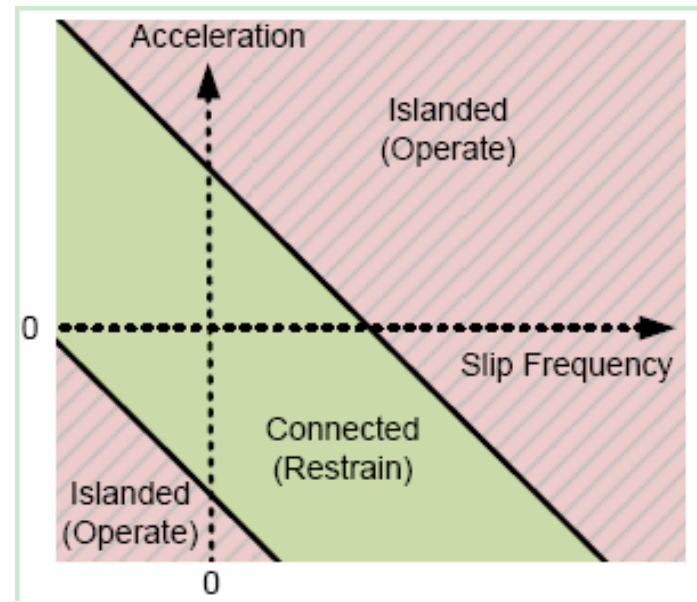

Figure A-4 Slip-acceleration islanding detection

\section{Simulation Result for Synchrophasor-based Islanding Detection [32]}

To verify the synchrophasor-based detection algorithm, our SEGIS team took advantage of Electromagnetic Transients Program (EMTP) and Real Time Digital Simulator $\left(\right.$ RTDS $\left.^{\circledR}\right)$ simulators for a variety of system configurations and an inverter based DG model, respectively.

\subsection{EMTP Simulation}

As discussed previously, one disadvantage in traditional islanding detection methods is the condition where the VMF is affected by system disturbance such as load changing. Some traditional islanding detection methods will trip the connection incorrectly. In this case, we simulated different cases including multi-inverter, multi-inverter case with engine-generator set, system-wide frequency event and large, local load-switching event. (Table A-3) The purpose of the simulation was to provide guidelines on the constraint regions which determine whether an islanding happens or not. As a model, the IEEE 
34-bus radial distribution feeder was used.

Table A-3 Cases Simulated in EMTP

\begin{tabular}{|c|c|c|}
\hline Case No. & Condition & Desired Result \\
\hline 1 & Multi-inverter case & Detect and trip \\
\hline 2 & Multi-inverter case with engine-generator set & Detect and trip \\
\hline 3 & System-wide frequency event & Ride through \\
\hline 4 & Large, local load-switching event & Ride through \\
\hline
\end{tabular}

Case 1 involved 18 PV inverters-one at each three-phase load bus in the 34-bus feeder. Case 2 involved 12 PV inverters and a 1 MVA engine-generator set using a synchronous generator. This is a difficult case for islanding detection because the slow dynamics of the engine-generator set resemble those of the grid from a synchrophasor standpoint. In Case 1 and Case 2, the real and reactive power were kept closely matched (to within about 0.2 percent), and the effective quality factor of the load was kept at or above 1.0. A higher quality factor makes it more difficult for the traditional frequency shift approach to detect an island because it takes more energy to move an islanded frequency away from the resonant frequency of the load. In Case 3, the frequency trajectory observed in the Italian blackout of 2003 was scaled to $60 \mathrm{~Hz}$ and used to simulate a wide-area frequency event in which a ride through is desired [33]. Finally, in Case 4, a large motor was placed distally on the feeder and switched on during the simulation. Case 4 was another instance in which it was desired that the local system not trip.

Figure A-5 aggregates the results, showing a scatter plot of the peak slip and acceleration values obtained in these cases. The red squares in Figure A-5 illustrate the slip and acceleration points that should be outside of the connected region and, therefore, result in a trip for Cases 1 and 2. The green asterisks represent the slip and acceleration 
values from Case 3 and Case 4 that must lie inside the connected region. The scatter plot provides guidance in selecting the connected versus islanded regions, which are shown in Figure A-4.

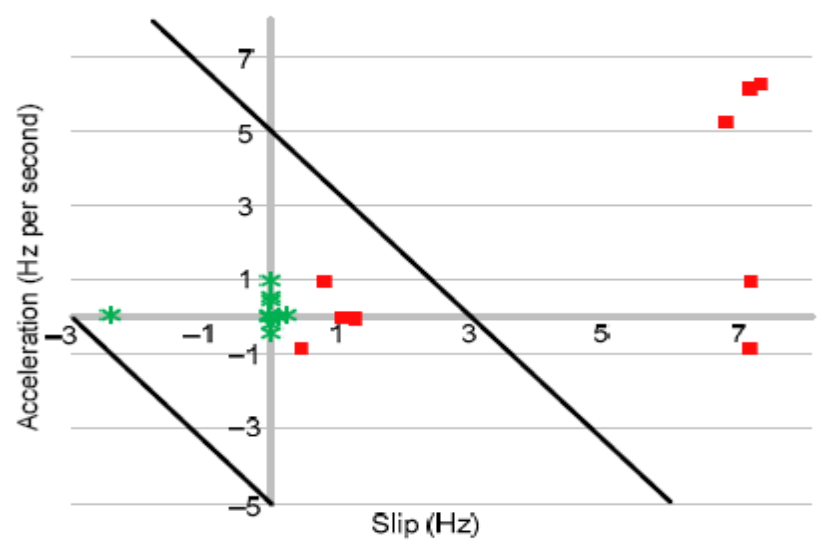

Figure A-5 Plot of the result of EMTP modeling and the recommended slip and acceleration boundaries

Most of the ride-through cases (green asterisks) lie close to the origin as would be expected; however, there is an outlier. One of the large motor-switching cases shows a large negative slip with no acceleration. Also, although one set of the detect-and-trip cases (red squares) is located in the upper-right portion of the plot, there are also a few detect-and-trip cases that are quite close in proximity to the ride-through cases on the slip horizontal axis point, near $1 \mathrm{~Hz}$. These points, which represent the engine-generator set case, present difficulties in designing appropriate constraint regions. The generator dynamics resemble those of the grid closely enough that islanding threshold selection is more challenging. These results indicate that when an engine-generator set is present, different thresholds are necessary. This detection challenge could be overcome with additional signal processing, statistical analysis, or pattern recognition. Based on the results of this section, the typical setting of the restraint region is a maximum acceleration of $5 \mathrm{~Hz}$ per second and a maximum slip of $3 \mathrm{~Hz}$. 


\subsection{RTDS Simulation}

After the restraint region is set, an inverter based DG model was developed and tested using the RTDS. As shown in Figure A-6, the inverter source on the left drives the distribution portion of the system through the point of common coupling at Bus B1. The main power system is to the right of Circuit Breaker CB1 and Bus B2. During an islanded condition, CB1 is open.

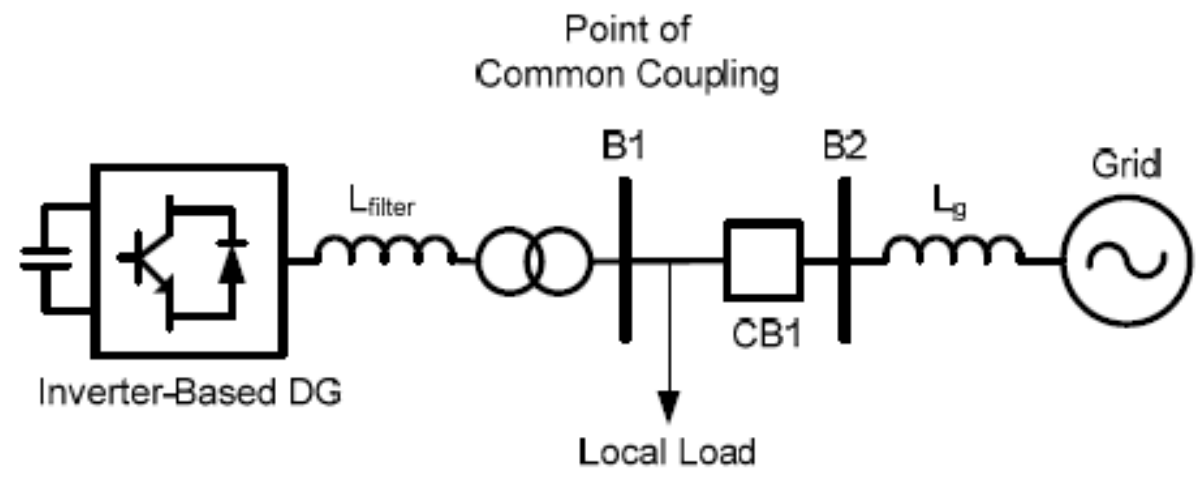

Figure A-6 Inverter-based system model for RTDS

In order to check for the most difficult case, the local load is closely matched to the DG. The grid is modeled as an infinite source behind small impedance. Under normal conditions in this case, no power is imported from the grid.

When connected to the grid, the voltage and frequency are maintained by the grid and the DG will supply constant current and inject maximum power. Presently, most DGs inject maximum real power, and the reactive power is driven to zero by the inverter [34]. When disconnected from the grid, the inverter operates in an islanded condition. In this case, the frequency is determined by the load resonating frequency [35]. In the RTDS islanding simulations presented in this thesis, the ratio of generation power to load power is in the range of 0.95 to 1.05 . Such cases are hard for traditional systems to detect 
because of the small mismatch in frequency.

Figure A-7 shows the simulation setup. The RTDS enables use of relays and controls coupled to a software model of the inverter and electric power system. Figure it shows the software model of the inverter and electric power system. In Figure A-8, the PV panels (left) are modeled with a constant source. The dc signal is modulated by the switch-mode inverter, consisting of six gate turn-off thyristor-diodes (GTO-diodes). There are two GTO-diodes for each phase. Each GTO-diode switch is controlled by a dc signal to either a conducting or non-conducting state. The right portion of Figure A-8 shows the local distribution load and the breaker connecting to the grid. The breaker in Figure 8 is the same as CB1 in Figure A-6.

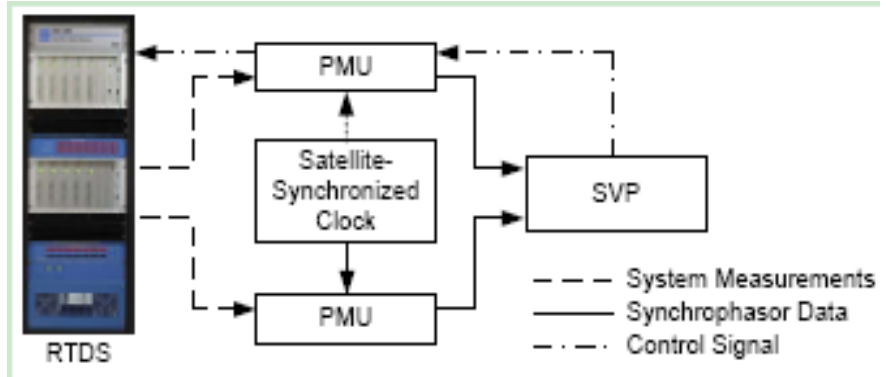

Figure A-7 RTDS simulation setup

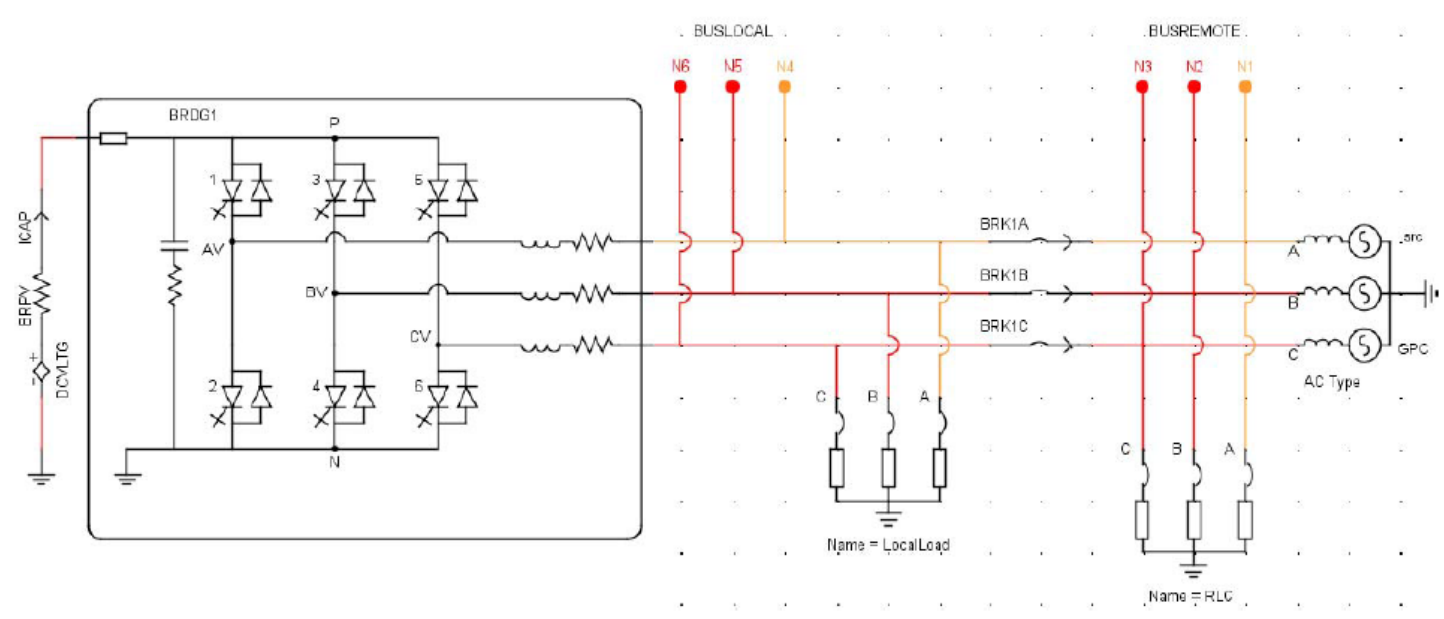

Figure A-8 System Diagram from RTDS 
Because of their electronic control, inverter-based generation sources respond quickly to changes in the power system, as compared with a synchronous machine. The frequency of a synchronous machine is constrained by the machine inertia and the dynamics of the generator mechanical controls. In contrast, the inverter has no mechanical constraints. When the distribution system islands, the PV inverter slows its frequency in response to the reference signal control algorithm. These control algorithms are not limited by mechanical constraints.

For this test, closed-loop simulation was performed by connecting the PMUs to the RTDS and generating the required time-synchronized measurements with the inverter and power system numerical models. The measurements from the PMUs were sent to the control device, where the synchrophasor-based islanding detection algorithm was implemented. Once the algorithm detected an island and output a trip signal, the signal was wired back into the RTDS to open the breaker, thus isolating the inverter from the local island. Two cases were considered—closed and open CB1.

\section{A. Closed CB1}

Figure A-9 shows the positive-sequence voltage angle difference between the local and remote sites when CB1 is closed. The display screen shows the bus voltage of both the local and remote locations, along with the reference frequency of the grid. 


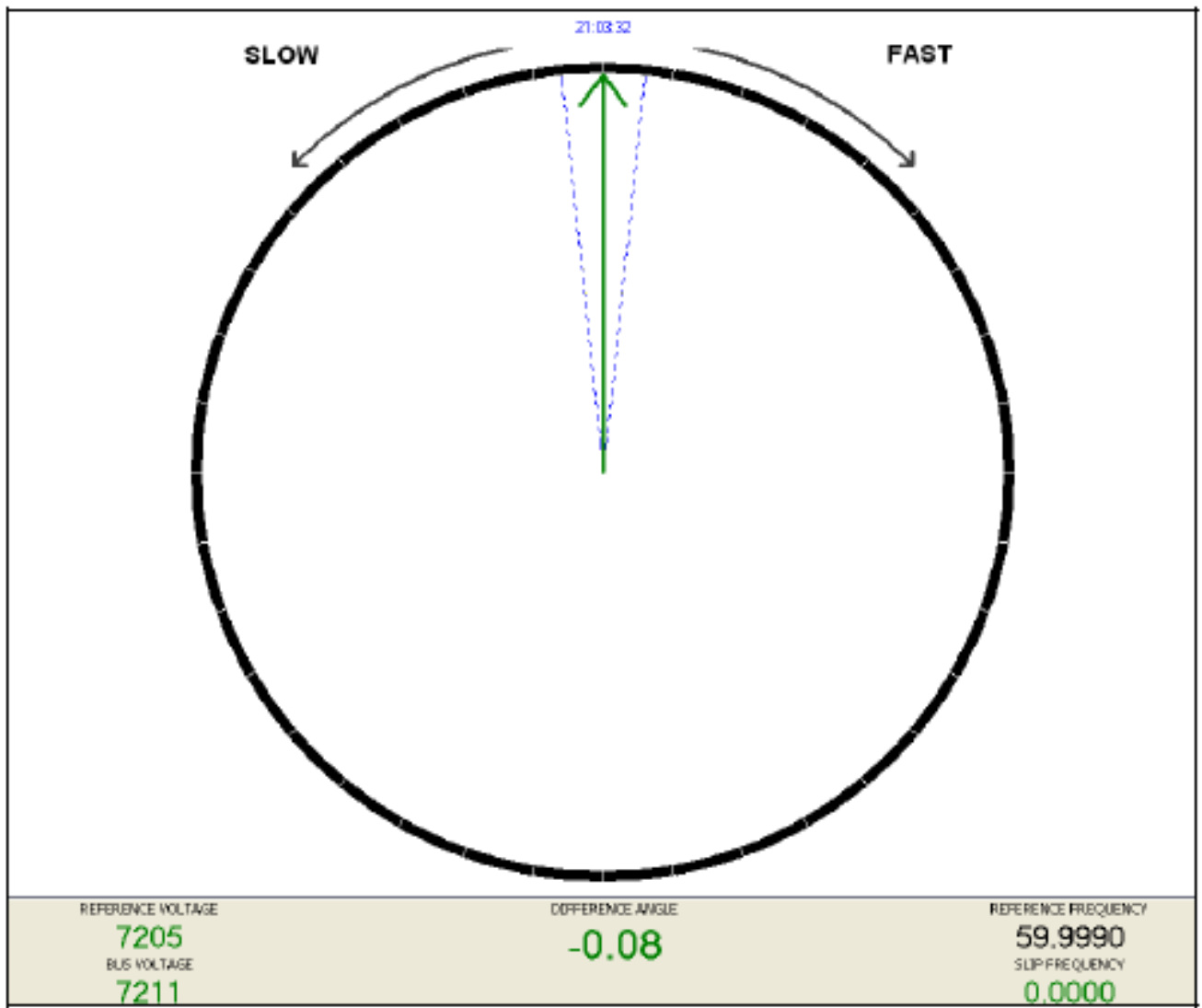

Figure A-9 Synchroscope display for connected system

\section{B. Open CB1}

Figure A-10 shows the angle difference and the slip frequency between the local and remote sites when CB1 is open and local load is closely matched with the DG output. During the disconnected state, the angle difference changes as the two systems slip in frequency with respect to each other. Because the two PMU locations are electrically close to each other, a threshold of 10 degrees is selected for the angle difference. A system study may be necessary to properly set this threshold to avoid a false island declaration. 


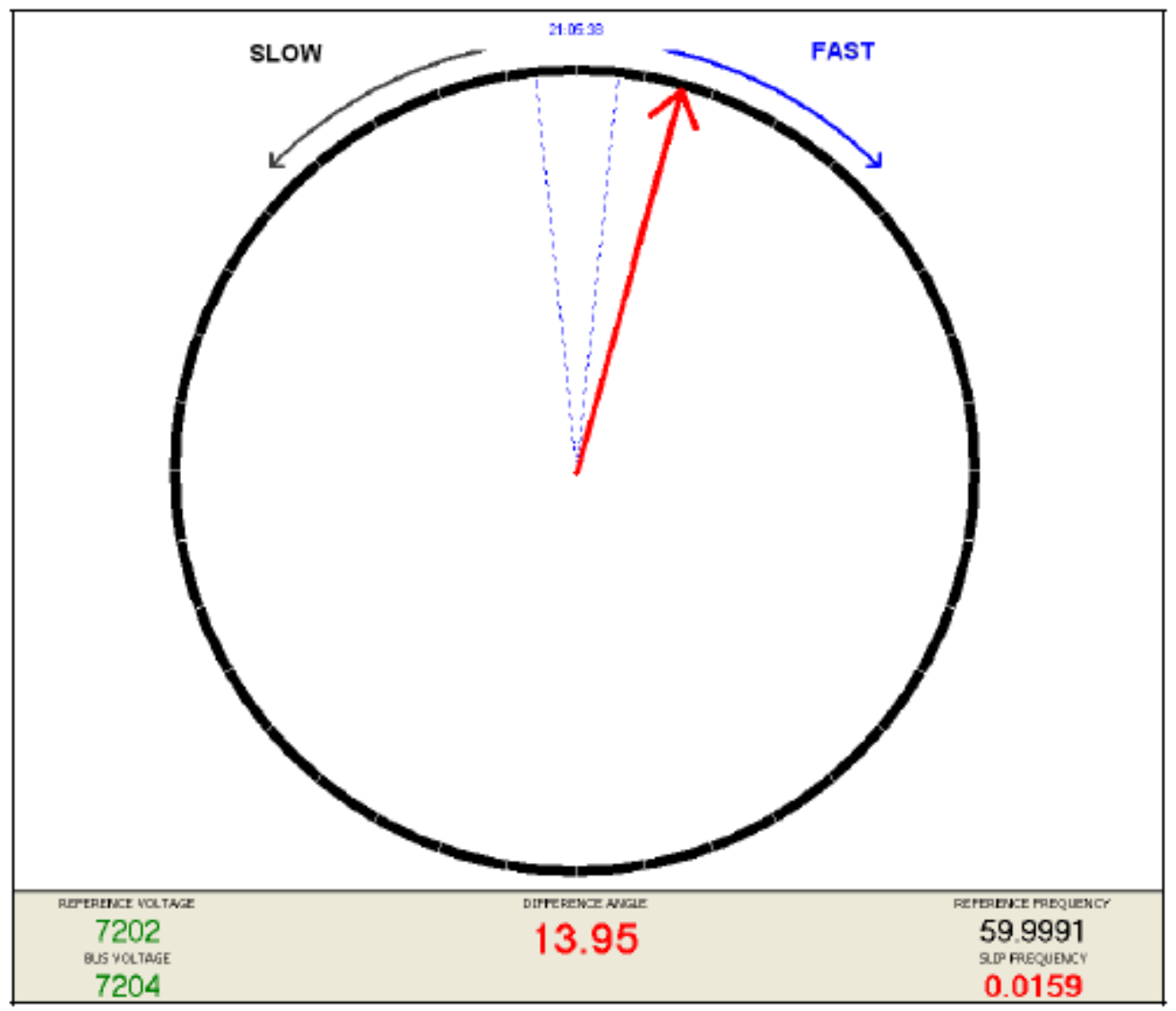

Figure A-10 Synchroscope display for disconnected state

Figure A-11 shows the plot of slip versus acceleration, which is obtained from the PMUs in the RTDS simulation. The slip threshold is set to $3 \mathrm{~Hz}$, and the acceleration threshold is set to $5 \mathrm{~Hz}$ per second, according to the EMTP-RV simulation results. Setting larger thresholds makes the system more secure; the system is less likely to false trip. Setting smaller thresholds makes the system more reliable because it is more likely to trip for an islanded case. Given the distribution bus location of many PV systems and the nature of the inverter, it is expected that slip and acceleration can have wide swings with very short time duration. In Figure A-11, Points 1, 2, 4, 5, and 6 are in the islanded region and can be used to disconnect the inverter from the local island. The time increment between each point is equal to the synchrophasor message period of 16.67 milliseconds 
(60 messages per second). Although the signals swing into the islanding characteristic, it is for a very short time. For example, even if Point 3 were in the islanded region, the total time spent outside of the connected constraint region is only 80 milliseconds. This is different than a synchronous-machine DG system. For synchronous machines, the slip and acceleration sustain beyond the thresholds for longer times [34]. This is because of the system inertia and rotating characteristics of the synchronous machines. For inverter-based DG with power electronic control, the slip and acceleration change much faster.

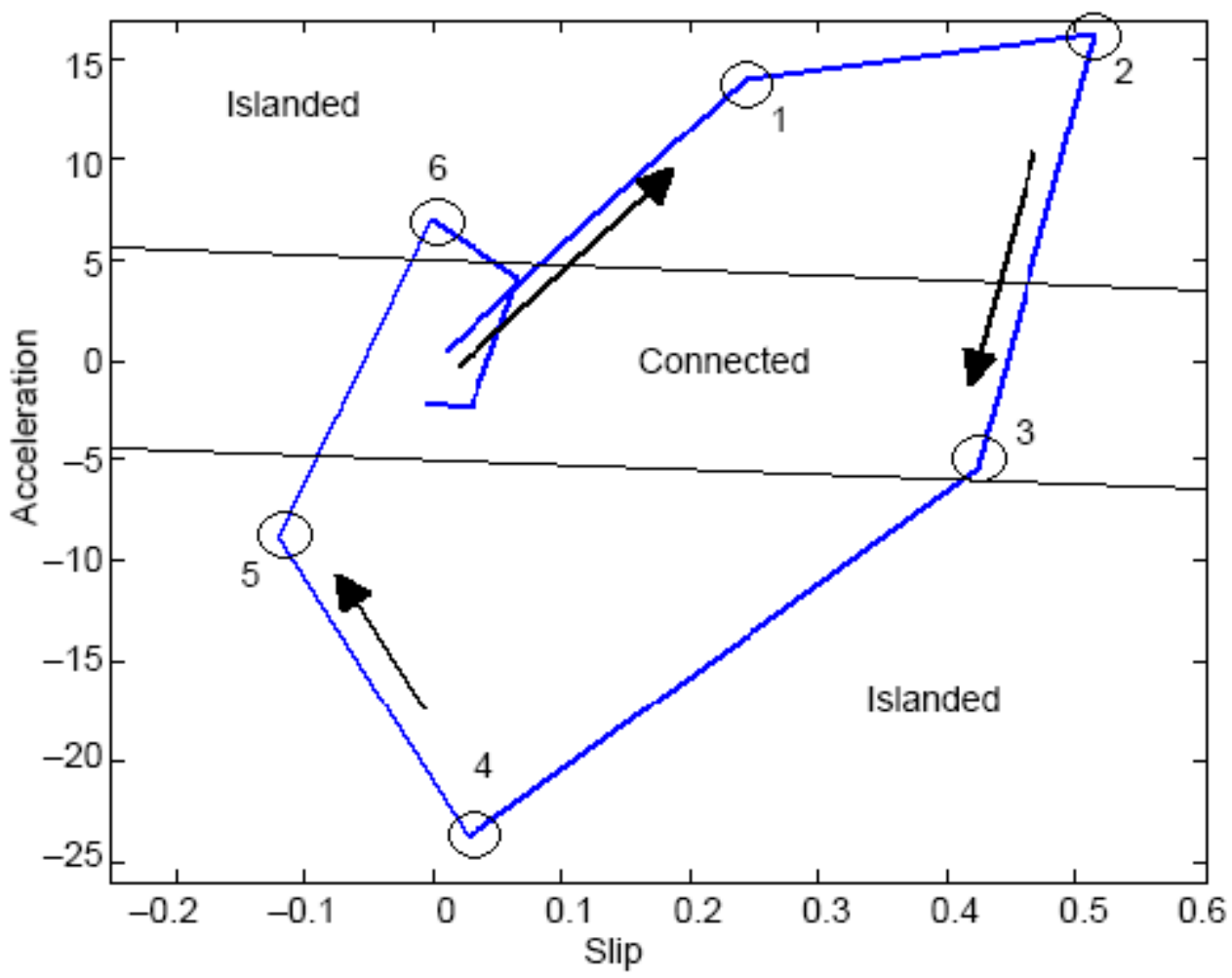

Figure A-11 Plot of slip and acceleration values

For this simulation case, the angle difference output detects the island, demonstrating the system provides a reliable islanding detection method for inverter-based islanding detection. When generation power is close to load power, the island is eventually 
detected, because some slip persists between the systems.

The behavioral characteristics and response times of the inverter-based DG are significantly different from traditional synchronous-machine DG because of the power electronics involved. Figure A-12 shows the combined angle difference, slip, and acceleration results from the RTDS. Notice the fast nature of slip and acceleration transients. They settle within 200 milliseconds. For security, a pickup timer on the slipacceleration islanded indication is set to greater than 200 milliseconds. For this case, the slip-acceleration condition does not result in the declaration of an islanded condition.
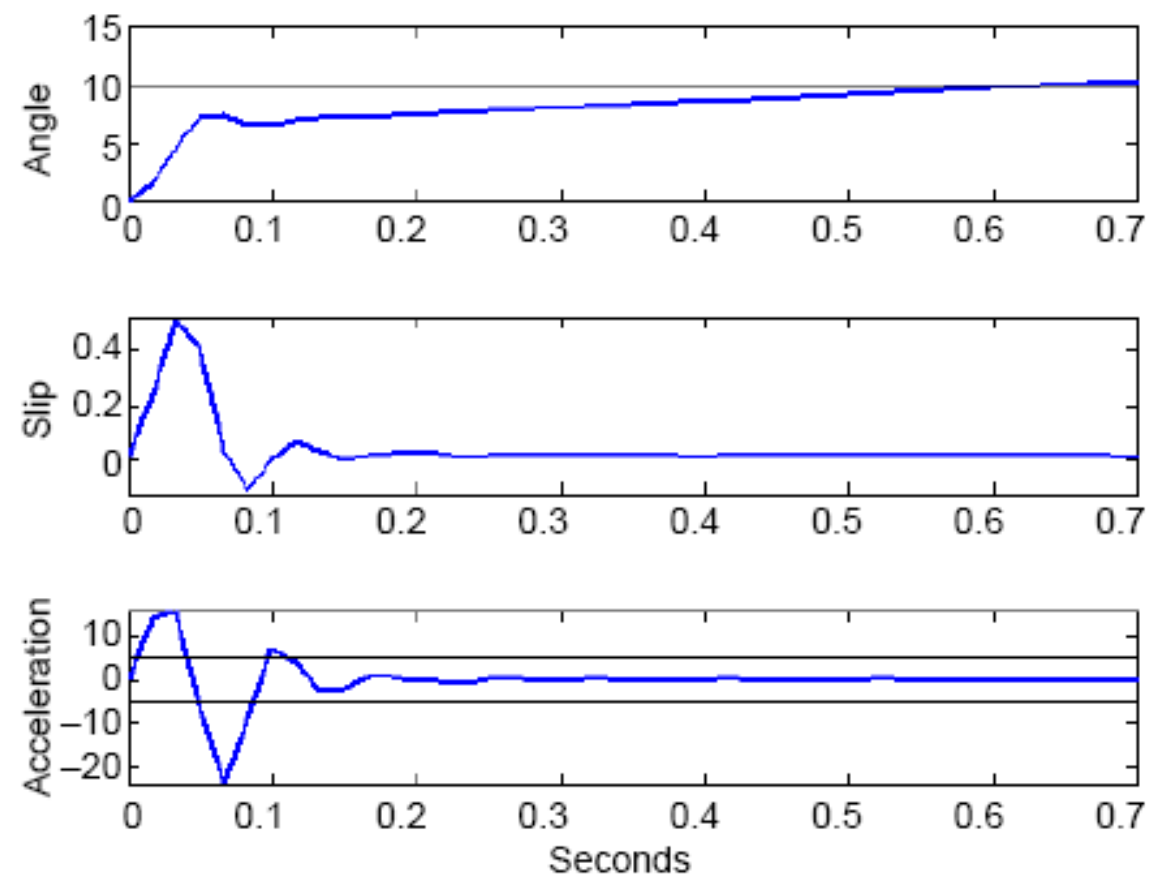

Figure 12 Angle difference, slip, and acceleration results from the RTDS

The slip settles to a non-zero value; therefore, the angle integrates until it reaches the 10-degree threshold and declares an islanded condition. Fig. 10 represents settling to a $0.02 \mathrm{~Hz}$ mismatch. In this case, the angle reaches a 10-degree threshold, and an island is declared at 700 milliseconds. This is well within the IEEE 1547 limit of 2 seconds. 


\section{SEGIS Demonstration}

The SEGIS live demonstration took place at one of the Prologis sites described in Chapter 3. Our SEGIS team selected a $260 \mathrm{~kW}$ inverter and built a mobile resistive-inductive-capacitive (RLC) test load rig which could island the inverter at full power output without disconnecting real customer loads. Relays that include PMU function were installed at the picked inverter, as well as at the governing substation. The islanding detection device (i.e. SVP) was also integrated into the inverter which will instantly and stably receive PMU data from endpoint to determine if the PV system was connected to the grid. Figure A-13 shows the system configuration. The PMU relay in the substation communicates to local SPV through $900 \mathrm{MHz}$ radio. The PMU reference used is from a remote substation which works as a clock. The total latency is about $50 \mathrm{~ms}$.

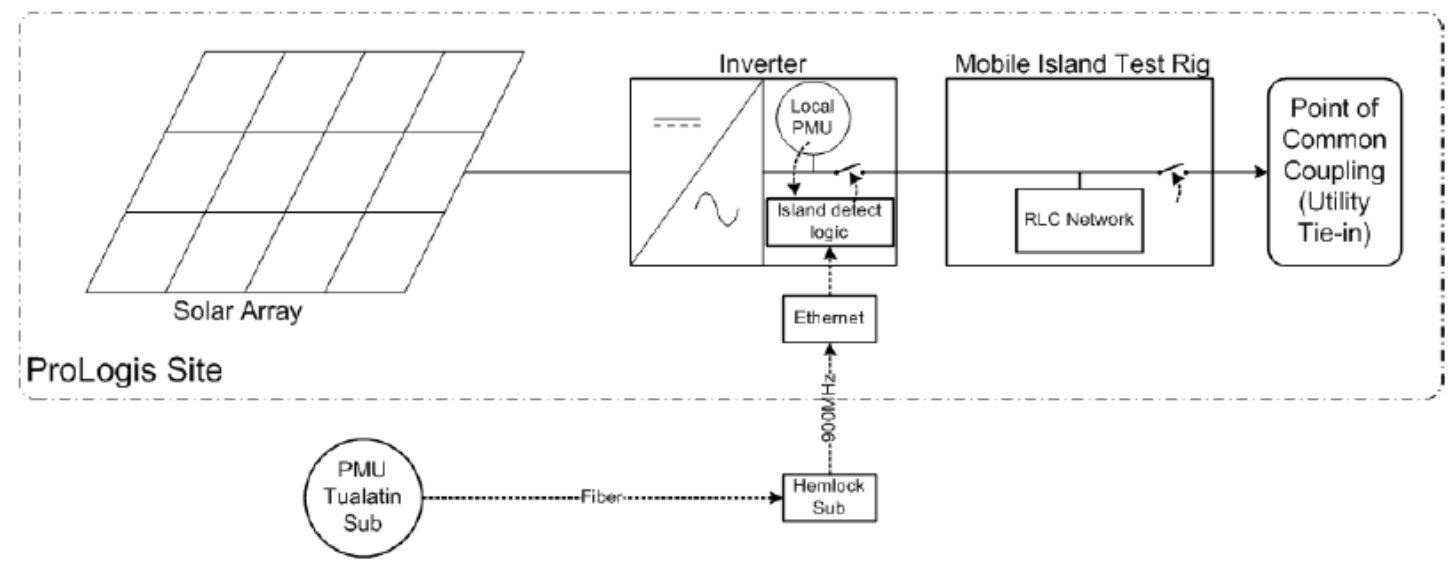

Figure A-13 Live demonstration system configuration

At the beginning of the demonstration, the anti-islanding device was disabled to set the rig load appropriately. The mobile RLC load test rig was tuned to $60 \mathrm{~Hz}$ at the representative available output power level of the PV system. During this time, the PV and tuned RLC load were connected directly to the grid. The grid-side currents were 
monitored and verified to be zero to ensure the system was properly tuned. Then the anti-islanding was enabled and the island was formed with opening the switch. The switch status was set to logic 1 to an oscilloscope and the islanding event was detected by disrupting the output of the inverter when the anti-islanding logic determined that the slip or acceleration passed the thresholds developed for islanding.

Figure A-14 Live anti-islanding demonstration results

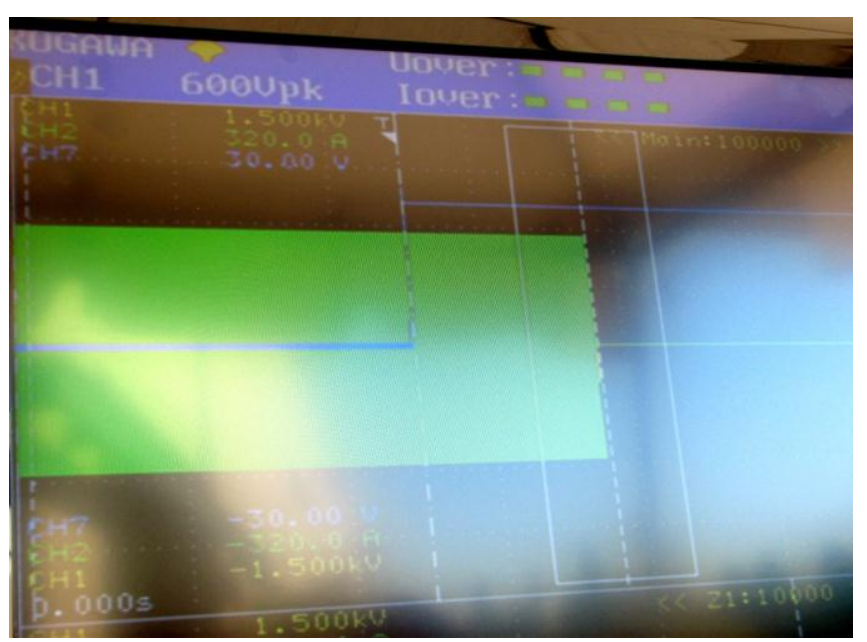

Figure A-14 shows the islanding event. The blue trace shows the start of the islanding event. The green band was the output power of the inverter and was controlled by the relay when an island event was detected. The time required to recognize and respond to the islanding event for this case was about 1.3 seconds. The result was slower than the lab testing. This could be due to the system parameters setting and the threshold setting. The team believes that the further improvement on restrain region threshold will bring more accurate and much faster on event detection than what was demonstrated at the Prologis site.

\section{Conclusion}

Synchrophasor-based islanding detection is one of the most efficient methods for anti-islanding. In this project, it was shown that it has good low-voltage ride through ability for system disturbance or unexpected fault. There is also low impact to the utility 
system in comparison with active detection methods. However, a better wide-area control algorithm and a more accurate restrain region threshold need to be developed in order to enhance this potential technology for use within future high-penetration networks. 